Génét. Sél. Evol., 1984, 16 (1), 57-84

\title{
Nouvelles données sur le déterminisme génétique et épigénétique de la monogénie chez le crustacé isopode terrestre Armadillidium vulgare Latr.
}

\author{
J.-J. LEGRAND et P. JUCHAULT \\ avec la collaboration technique de Gabriel HeILy et Catherine Le Bote \\ Laboratoire de Physiologie et Génétique des Crustacés, E.R.A. C.N.R.S. $n^{\circ} 230$ \\ 40, avenue du Recteur-Pineau, $F 86022$ Poitiers Cedex
}

\section{Résumé}

La monogénie d'Armadillidium vulgare a été rapportée à l'action de différents facteurs. Les uns, féminisants, à transmission matrocline, transforment les mâles génétiques (homogamétiques) en néo-femelles : l'un, F, est une bactérie responsable des descendances thélygènes $\left(T_{F}\right)$ dont les femelles sont réfractaires à la masculinisation; $f$ et $\mathbf{f}^{\prime}$ induisent respectivement l'arrhénogénie $\left(\mathrm{Ar}_{\mathrm{f}}\right)$ et la thélygénie $\left(\mathrm{T}_{\mathrm{f}}\right)$ à femelles masculinisables. Le facteur $\mathrm{m}$ s'oppose, dans certains croisements, à l'action des facteurs féminisants et induit l'intersexualité ou un maintien du phénotype mâle.

Les nouvelles données se rapportent à la transmission des facteurs $f$ et $\mathrm{f}^{\prime}$. Alors que la transmission matrocline de $\mathrm{f}^{\prime}$ est régulière, la transmission patrocline est incomplète. Environ $1 / 3$ des mâles d'une descendance $T_{f}$, croisés avec une femelle amphogène transmettent la thélygénie, avec souvent une atténuation du taux de néo-femelles. Environ $1 / 3$ de leurs fils sont également capables - dans le même type de croisement - de transmettre les facteurs féminisants hérités de leur père, mais le taux de transmission est très faible. Les petits-fils ne transmettent plus ces facteurs.

Les néo-mâles expérimentaux transmettent la thélygénie et l'arrhénogénie d'une façon comparable à celle offerte par les femelles dont ils sont issus. Ces données sont comparées à celles qui concernent la transmission du virus $\sigma$ de la drosophile. Il est souligné des convergences entre l'état stabilisé du virus $\sigma$ et la thélygénie $T_{f^{\prime}}$, ainsi qu'entre l'état non stabilisé de ce virus et l'arrhénogénie $\operatorname{Ar}_{\mathrm{f}}$. Dans les 2 cas, l'action du contexte génétique est comparable et permettrait d'expliquer le passage de la thélygénie à l'arrhénogénie constaté dans différents croisements.

Ces résultats génétiques sont cependant encore incapables de trancher définitivement la question : $f$ et $\mathrm{f}^{\prime}$ sont-ils des polygènes ou des facteurs épigénétiques? Des arguments génétiques et physiologiques complémentaires tendent à appuyer l'hypothèse que $\mathrm{f}$ est soit un virus parasitant la bactérie $F$, soit un plasmide de cette bactérie, intégré aux cellules de l'Oniscoïde. La perte de $f$ chez tout ou partie des descendants d'une néo-femelle $\mathrm{Ar}_{\mathrm{f}}$ expliquerait l'arrhénogénie et l'augmentation régulière du taux des mâles dans les portées successives d'une femelle fécondée par un seul mâle (allélogénie).

Ces données sont discutées dans un contexte phylogénique fondé sur l'étude précédente de 16 populations et d'une population nouvelle paraissant - comme d'autres - uniquement constituée de mâles génétiques et de néo-femelles. La sélection naturelle, jouant sur 
le contexte génique susceptible de contrôler l'effet des facteurs $f$ et $f^{\prime}$, maintient un taux de 55 à 60 p. 100 de femelles. Les femelles génétiques ne subsistent que dans certaines populations offrant des descendances dont l'amphogénie est stable en inbreeding et correspond au mécanisme ancestral de détermination du sexe. La bactérie - ou le virus - ne subsisterait plus, dans certaines populations, que sous la forme d'un fragment d'ADN (plasmide).

Mots clés : Monogénie, Oniscoïdes, bactérie, plasmide, populations.

\section{Summary}

New data on the mechanisms of monogeny in Armadillidium vulgare Latr. (Crustacea, Oniscoidea)

In previous papers we have discussed the monogeny which is found in numerous populations of $A$. vulgare and which may be caused by various factors : $\mathrm{F}, \mathrm{f}, \mathrm{f}^{\prime}$ or $\mathrm{m}$. $\mathrm{F}$ is a symbiotic intracellular bacterium which induces a thelygeny $\left(T_{F}\right)$ by converting almost all the genetic $\hat{\delta} \hat{\delta}$ progeny to neo- $q$ ㅇ‥ In populations where $F$ exists (e.g. Niort) genetic $q q$ seem to have disappeared and all $q q$ are neo- $q q \mathrm{ZZ}_{\mathrm{F}}$. The $\hat{\delta} \hat{\delta}$ descend from the neo- $q q Z_{\mathrm{f}}$ which differ from the neo- $q q Z_{F}$ in that it is possible to masculinize them with an implanted androgenic gland, not possible with the neo- o \& $\mathrm{ZZ}$. In broods deriving from neo- $q$ $q \mathrm{ZZ}_{\mathrm{f}}$ fertilised by a single male the incidence of neo- $q$ \% may fall to zero, producing an arrhenogeny $\left(\mathrm{Ar}_{\mathrm{f}}\right)$. In many populations another form of thelygeny $\left(\mathrm{T}_{f^{\prime}}\right)$ occurs in which all female progeny are neo- $q$ $\mathrm{ZZ}$ as in $\mathrm{Ar}_{\mathrm{f}}$ lineages, but the incidence of neo- $q \circ \mathrm{ZZ}_{\mathrm{f}}$, does not change in subsequent broods of these females fertilised by a single male.

In some populations (e.g. Nice) these are both genetic $q$ \& $(\mathrm{ZW})$ which have amphogenic (A) progeny (sex-ratio $=1$ ), and neo- $q$ \& which produce $\mathrm{Ar}_{\mathrm{f}}$ of $\mathrm{T}_{\mathrm{f}}$, lineages. The f- $f^{\prime}$ factors may be transmitted by males and females alike. The $\mathrm{m}$ factor is responsible for the formation of intersexes in the lineages $T_{F}, T_{f}$ and $A r_{f}$. This $m$ factor is found in the $\hat{\delta} \delta$ with female genital apertures $\left(\hat{\delta}_{\mathrm{og}}\right)$, and, in crosses between a $\delta$ og and a genetic $q$ it can convert the sex of $50 \mathrm{p} .100$ of the genetic $q$ if progeny into neo- $\hat{\delta} \hat{\delta}$ or $\hat{\delta} \hat{o}$ og.

The new data presented concern the mode of transmission of the $f$ and $f^{\prime}$ factors. Although the matroclin transmission of $\mathrm{f}^{\prime}$ is regular the patroclin transmission is incomplete : about $1 / 3$ of the males of a $T_{f}$, lineage crossed with a female (A) transmit thelygeny, $1 / 3$ of their sons transmit it weakly, whereas their grandsons do not transmit $f^{\prime}$. When comparing these data to those concerning the Drosophila $\sigma$ virus we note similarities between the stable state of this virus and the $T_{f}$, thelygeny, and also between the non-stable state of the virus and the $\operatorname{Ar}_{\mathrm{f}}$ arrhenogeny. In both cases the action of the genotype is similar, and such a mechanism could account for the transition from thelygeny to arrhenogeny observed in the various crosses. The possible polygenic or epigenetic nature of $f$ and $\mathbf{f}^{\prime}$ is discussed.

In an experiment in which neo- $q$ $\mathrm{ZZ}_{\mathrm{F}}$ tissue was implanted in a genetic $q$ crossed with a male (A) the progeny was thelygenic $(2 \hat{\delta}, 23 \%)$. The progeny of 14 of these $F_{1}$ females were then studied for five generations by inbreeding or crossing with (A) males, this gave the following results : 12 females produced thelygenic or allelogenic progeny resulting from the transmission of the symbiotic bacterium; one (a non-infected genetic \&) gave amphogenic progeny; and one gave arrhenogenic progeny of which the daughter females could be experimentally masculinised (indicating the presence of $f$ and the absence of $F$ ). This $f$ factor which does not exist in the amphogenic lineage (stable fore 14 generations) was introduced by the implant. The causative agent may be a virus which exists in the bacterium as a provirus, or as part of the bacterial DNA (a plasmid). It would retain the property of the bacterium to inhibit the differentiation of the androgenic gland, but not the function of a gland implant. Its disappearance during the successive oogenesis of a neo- $q \mathrm{Ar}_{\mathrm{f}}$ would explain the arrhenogeny. Such an explanation could account for observations in a population of $A$. vulgare collected at Argenton-sur-Creuse. 
A review of the various kinds of sex-determination in 17 populations of $A$. vulgare supports the hypothesis of an evolutionary progression form amphogeny to $T_{r}$ thelygeny, and then to $T_{f}$, thelygeny associated with $A r_{f}$ arrhenogeny as the genetic females decrease and disappear. At present the bacterium seems to the decreasing, but its plasmid (or virus) $f$ could persist in many populations, some of them keeping genetic females.

Key words : Monogeny, Oniscoidea, bacterium, plasmid, populations.

\section{Introduction}

L'existence de la monogénie chez certaines espèces d'Oniscoïdes, notamment Armadillidium vulgare, a été découverte par VANDEL (1938, 1941). Cet auteur a montré que les femelles, considérées comme seules responsables du phénomène, sont, les unes thélygènes $(T)$, donnant exclusivement - ou en majorité - des femelles, les autres arrhénogènes (Ar), dont la descendance est entièrement - ou surtout - constituée de mâles. Certaines descendances, qualifiées d'allélogènes, offrent une alternance de portées différant significativement par la sex-ratio.

Le mécanisme de la monogénie a fait l'objet, chez les Crustacés Péracarides, de très nombreuses études. Vandel avait d'abord proposé une explication fondée sur l'hypothèse d'une hétérogamétie de la femelle des Oniscoïdes et d'une disjonction préférentielle des hétérochromosomes dans les ovocytes. Ultérieurement (1941), cet auteur penchait pour une détermination phénotypique du sexe chez ces animaux. DE LATTIN $(1949,1951,1952)$, après avoir mis en évidence, chez différentes espèces d'Oniscoïdes, le rôle de «réalisateurs du sexe» joué par certains gènes conditionnant la couleur du corps, en déduit que le déterminisme du sexe ne peut être fondé sur l'existence d'hétérochromosomes. Cet auteur propose au phénomène de monogénie une explication polyfactorielle mettant en jeu d'une part, un couple d'allèles qui, sous sa forme dominante, $\mathrm{F}^{\prime}$, exerce une action féminisante relative, avec effet prédéterminant, d'autre part, un deuxième couple d'allèles, à rôle intensificateur, qui, sous la forme dominante $(\mathrm{I})$, assure à $\mathrm{F}^{\prime}$, ou à son produit cytoplasmique $(\varphi)$, une épistasie absolue. La constitution des femelles thélygènes serait $F$ f'II, celle des mâles de descendance arrhénogène $f^{\prime} f^{\prime} I I$; la lignée amphogène serait homozygote pour l'allèle i. ANDERS (1957) retrouve, chez l'amphipode Gammarus pulex subterraneus, une influence sur le sexe exercée par des gènes de couleur, $R^{2}, r^{+}$et $r: R^{2}$ et $r$ entraînent un accroissement du taux des mâles; les femelles sont, par contre, en excès dans les lignées $r^{+} r^{+}$. Vitagliano-Tadini (1963) explique la monogénie de l'isopode Asellus aquaticus par un mécanisme oligogénique.

Depuis ces travaux, l'existence d'un déterminisme du sexe fondé sur l'homo-hétérogamétie, reconnue chez de nombreux crustacés par examen du caryotype, a été étendue à un certain nombre de péracarides. C'est le cas pour l'amphipode Anisogaminarus anandalei (NilYama, 1950), où le mâle est XY. C'est également le cas des isopodes asellotes de la super-espèce Jaera albifrons (STAIGER \& BocQUET, 1954, 1956), où la femelle est $\mathrm{W}_{1} \mathrm{~W}_{2} \mathrm{Z}$, et du sphéromien Tecticeps japonicus, où le mâle est $\mathrm{X}(\mathrm{O})$ (NiIYAma, 1956). Chez l'isopode valvifère Idotea balthica, TinTURIER-HAMElin (1963) a établi, par l'étude de gènes liés au sexe, que la femelle est WZ, et ce fait a été confirmé par croisement de deux individus de même sexe génétique (LEGRANDHamelin, 1977). C'est à l'aide de cette dernière méthode que Katakura (1967), 
puis Juchault \& LEgrand (1972) démontrent l'état hétérogamétique, WZ, de la femelle d'Armadillidium vulgare; ces mêmes auteurs (1964) ont montré l'état homogamétique de la femelle d'Helleria brevicornis et de Porcellio dilatatus dilatatus; chez la sous-espèce Porcellio dilatatus petiti, c'est la femelle qui est hétérogamétique (LEgRAND \& JuChault, 1974 ; LEgRAND et al., 1974 b, 1980). Il en serait de même, par examen du caryotype, chez Porcellio laevis et $P$. rathkei (Mittal \& Pahwa, 1980, 1981). Chez les amphipodes Orchestia gammarellus et $O$. montagui, Ginsburger-VogEL (1973) a démontré l'homogamétie femelle.

Nous avons rapporté (Juchault et al., 1980 a) le déterminisme de la monogénie d' $A$. vulgare à l'intervention de plusieurs types de facteurs transmissibles : $F, f-f^{\prime}$ et $\mathrm{m}$.

- Le facteur $F$ est une bactérie se comportant comme un symbionte endocellulaire, présent dans tous les types cellulaires de l'hôte, à transmission matrocline par suite d'une infestation des ovocytes (MARTIN et al., 1973), thermosensible (JuchaulT et al., $1980 \mathrm{~b})$. Il transforme en néo-femelles $\left(\mathrm{ZZ}_{\mathrm{F}}\right)$ ou en intersexués tous les mâles génétiques issus de zygotes infestés, d'où en résulte une thélygénie souvent totale $\left(T_{F}\right)$. La bactérie $F$ peut être introduite dans un individu indemne (mâle ou femelle) par implantation de tissus quelconques de néo-femelles $Z Z Z_{\mathbf{F}}$. Lorsque le receveur est une femelle génétique $(\mathrm{ZW})$ (caractérisée par une descendance amphogène : sex-ratio $=1$ ), les portées ultérieures sont alors thélygènes (LEGRAND \& JUCHAULT, 1970). Un receveur mâle est transformé en intersexué (iM) offrant une hypertrophie des glandes androgènes, ces dernières continuant à synthétiser l'hormone mâle (JuCHAULT et al., 1978), mais ne semblant pas la libérer. La bactérie agit en perturbant le fonctionnement des systèmes de neurosécrétion contrôlant le fonctionnement de la glande androgène (Juchault \& Legrand, 1968, 1978 ; MARTiN, 1981). Les néo-femelles $Z_{\text {F }}$ (de même que les femelles $\mathrm{WZ}_{\mathrm{F}}$ ) ne sont pas masculinisables par implantation de glande androgène (LEGRAND \& JUChaulT, 1969 a).

Les facteurs $f$ et $\mathrm{f}^{\prime}$ sont également responsables d'une inversion sexuelle des mâles génétiques en néo-femelles $\mathrm{ZZ}_{\mathrm{f}-\mathrm{f}^{\prime}}$ ou en intersexués, mais ces néo-femelles sont masculinisables par implantation d'une glande androgène. Ces facteurs $f-f^{\prime}$ sont de nature inconnue : contrairement à la bactérie $F$, ils n'ont pu être mis en évidence par la microscopie électronique. Ils sont transmissibles par la voie matrocline mais ne peuvent être introduits par implantation de tissus de néo-femelle chez un receveur amphogène (A).

- Le facteur f peut être qualifié de labile : il semble absent de nombreux ovocytes pondus par la néo-femelle, de telle sorte que le croisement : of $\mathrm{ZZ} \times$ néo- ? $\mathrm{ZZ}_{\mathrm{f}}$ donne une arrhénogénie $\left(\mathrm{Ar}_{\mathrm{f}}\right)$ qui s'accentue souvent au cours des portées successives (le stock de spermatozoïdes apporté par la fécondation étant valable pour plusieurs pontes), et d'une génération à l'autre, par croisements consanguins, jusqu'à aboutir à des descendances exclusivement constituées de mâles. En même temps, lorsqu'il existe des intersexués, leur nombre diminue et finit par s'annuler (LEGRAND \& Juchault, 1969 b). Cette allélogénie des descendances $A_{\mathrm{f}}$ nous a incités à émettre l'hypothèse que $\mathrm{f}$ est de nature épigénétique.

- Le facteur $\mathrm{f}^{\prime}$ est plus stable que $\mathrm{f}$ et responsable, de ce fait, d'une thélygénie $\left(T_{f^{\prime}}\right)$. Des croisements entre individus issus de populations différentes ont montré que la transmission de $\mathrm{f}^{\prime}$ est contrôlée par un mécanisme génétique (JuchaulT \& Legrand, 1976 a). Par ailleurs, des mâles issus de descendances $T_{f^{\prime}}$ peuvent transmettre la thélygénie (Juchault \& LegRand, 1981 b). 
Nous avons émis l'hypothèse d'une possibilité de passage de $f^{\prime}$ à $f$. Des descendances de type $T_{f^{\prime}}$, issues d'une population récoltée à Nice (Alpes-Maritimes), ont en effet donné, après plusieurs générations marquées par une persistance de la thélygénie, des descendances de type $\mathrm{Ar}_{\mathrm{f}}$.

Le facteur que nous avons appelé $m$ est masculinisant et transmissible par la voie patrocline. Sa présence, associée à celle des facteurs féminisants, se révèle par la production d'intersexués, à la fois dans les lignées $T_{\mathrm{F}}$ - où l'on observe tous les intermédiaires entre les mâles normaux et les néo-femelles (iM, iMF, iF) - (LEGRAND et al., 1974 a) et dans les descendances $A_{\mathrm{f}}$ et $\mathrm{T}_{\mathrm{f}}$, où les intersexués sont représentés par des femelles (fertiles) à apophyse génitale mâle $\left(q_{\mathrm{ap}}\right)$ et des mâles (fertiles) à ouvertures génitales femelles ( $\delta_{o g}$ ) (Legrand \& Juchault, 1969 a) - Considéré initialement comme susceptible d'être épigénétique, $m$ n'a jamais pu être introduit par implantation de tissus de $\delta \delta_{0 g}$ chez une femelle amphogène. Par croisement d'un $\hat{\delta}$ og issu d'une descendance $\mathrm{Ar}_{\mathrm{m}}$ (riche en ce type d'intersexués) avec une femelle amphogène, ce facteur $\mathrm{m}$ s'est montré capable d'inverser 50 p. 100 des femelles filles - qu'elles soient WZ ou WW - en néo-mâles ou en $\hat{o}^{\hat{\delta}} \hat{o}_{\mathrm{og}}$; cette inversion semble ainsi contrôlée par un mécanisme génétique qui a été rapporté à l'action d'un gène majeur susceptible de présenter 2 états allèles (JuchaulT \& LegRAND, 1976 b).

L'étude de 16 populations françaises, espagnoles et nord-africaines d'Armadillidium vulgare (JUCHault et al., 1980 a ; JUChault \& LEgRAND, 1981 a et b) a révélé des modalités variées de détermination du sexe. Chez certaines, persistent des lignées amphogènes (sex-ratio $=1$ ), où ce déterminisme répond au mécanisme classique, avec hétérogamétie femelle. Dans la plupart des cas, intervient conjointement avec le précédent ou, semble-t-il, exclusivement, différentes formes de monogénie.

Chez Armadillidium nasatum, l'étude de la population de Niort (Juchault \& LEGRAND, 1979) a permis de confirmer l'état hétérogamétique (XY) du mâle de cette espèce déjà stipulé par LuEKEN (1966), et de rapporter la thélygénie - considérée par cet auteur comme étant d'origine génétique - à l'action d'une bactérie paraissant identique à celle de la lignée $T_{F}$ d'Armadillidium vulgare.

Un déterminisme épigénétique de la monogénie a été révélé chez des amphipodes. Bulnheim $(1965,1971)$ a montré que la thélygénie de certaines populations de Gammarus duebeni est due à une infestation par une microsporidie féminisant les mâles. Une salinité élevée ou une basse température affecte le degré de linfestation et, par voie de conséquence, la détermination du sexe. GinsBurger-Vogel (1973, 1974, 1980) explique les phénomènes de monogénie et d'intersexualité de la population de la Penzé (Finistère) d'Orchestia gammarellus par l'action d'un facteur épigénétique thermosensible, appartenant à une nouvelle famille de Cnidosporidies, qui féminise les mâles (hétérogamétiques).

Plusieurs problèmes concernant la monogénie d'Armadillidium vulgare ont été abordés dans la présente étude : d'une part, l’analyse de données concernant le mode de transmission, la nature du facteur $f$ et la relation entre les facteurs dénommés $f$ et $\mathrm{f}^{\prime}$, d'autre part, la signification, en termes d'évolution, des différentes formes de monogénie. Il est en effet curieux que, dans certaines populations - dont une nouvellement étudiée ici - coexistent plusieurs formes de thélygénie $\left(T_{F^{*}}\right.$ et $\left.T_{f^{\prime}}\right)$, alors que, dans d'autres, s'observe seule la thélygénie $T_{f^{\prime}}$, la source presque exclusive des mâles étant, dans les deux cas, les descendances arrhénogènes $\mathrm{Ar}_{\mathrm{f}}$. On peut se poser la question : $T_{f^{\prime}}$ dérive-t-elle de $T_{F}$ ? 
Par ailleurs, dans les populations où la monogénie a totalement supplanté l'amphogénie, comme à Niort (Juchault et al., $1980 \mathrm{a}$ ), où la thélygénie est essentiellement due à $\mathrm{F}$, les femelles génétiques semblent disparues. Dans cette population tous les individus sont probablement des mâles génétiques dont 55 à 60 p. 100 sont inversés en néo-femelles. Il en est probablement de même dans des populations comme Moulis (Juchault \& Legrand, 1981 b), où toutes les descendances étudiées ont été monogènes, et la thélygénie uniquement du type $T_{f^{\prime}}$. Du fait que les femelles $\operatorname{Ar}_{f}$ - qui sont la seule source importante de mâles - disparaissent dans les générations consanguines, il est évident que la survie de la population dépend d'un renouvellement de ces femelles. Or, à Niort, les mâles ne peuvent essentiellement s'accoupler qu'avec des femelles $T_{F}$ qui transmettent la bactérie féminisante. La même question peut donc se poser : le facteur $f$ peut-il dériver de $F$ ? Dans une population comme celle de Moulis, la filiation $f^{\prime} \rightarrow f$ semble obligatoire pour assurer la pérennité de l'espèce.

\section{Matériel et méthodes}

La mise en évidence, dans une descendance simplement caractérisée par la sexratio, de l'intervention de différents facteurs contrôlant le sexe, qu'ils soient épigénétiques ou génétiques, nécessite l'emploi d'une souche de référence stable, dont les mâles et les femelles seront croisés avec les individus composant la descendance indéterminée. Nous avons utilisé la souche amphogène (A) de Nice qui nous a permis de démontrer l'hétérogamétie femelle (JuchaulT \& LEgRAND, 1972) et dont la sexratio $(1 / 1)$ a été parfaitement stable en 15 générations. Des néo-mâles expérimentaux, issus d'une inversion sexuelle de jeunes femelles niortaises par implantation de glande androgène, ont également été croisés avec des femelles (A). De tels néo-mâles ne peuvent évidemment être obtenus que dans les lignées $A r_{f}$ et $T_{f}$, dont les femelles sont masculinisables. Ces différents types de croisements ont été employés, d'une part, pour confirmer la transmission de la thélygénie $T_{f^{\prime}}$ par les mâles (naturels) et voir, notamment, si les descendants d'un mâle thélygène sont — ou non — capables de transmettre à leur tour cette thélygénie, d'autre part, pour étudier la possibilité d'une transmission du facteur $f$ par un néo-mâle expérimental. Ainsi, partant d'une descendance $T_{f}$, le caractère thélygène d'un mâle ou d'une femelle de cette $F_{1}$ est déterminé par l'observation de la sex-ratio du croisement $\left(\mathrm{CRF}_{22}\right)$ de cet individu avec une femelle ou un mâle (A). Il en sera de même pour le caractère thélygène d'un individu issu d'un tel $C_{2 R}$. Le même type d'analyse a été poursuivi dans certains cas jusqu'à la $6^{\mathrm{e}}$ génération.

L'étude de l'évolution du type de descendance offerte par une femelle (A) fécondée par un mâle frère, après infestation par la bactérie $F$, a été effectuée en analysant la sex-ratio de la descendance de la femelle receveuse au cours de 5 générations successives. Ont été également effectués des tests physiologiques consistant à implanter une glande androgène chez les femelles des différentes decendances : la réussite - ou l'échec - de la masculinisation révèle respectivement l'absence - ou la présence de la bactérie $F$.

Les modalités de l'étude d'une nouvelle population, celle d'Argenton-sur-Creuse (Indre) sont les mêmes que précédemment (Juchault et al., 1980 a), à savoir : l'étude de la sex-ratio de la descendance de femelles récoltées fécondées, celle des filiations 
ultérieures en inbreeding ou par croisement avec la souche (A) de Nice, enfin le test physiologique exposé ci-dessus, qui permet de statuer sur la présence - ou l'absence de la bactérie $F$.

\section{Résultats}

\section{A. Transmission de la thélygénie $T_{f^{\prime}}$ par les mâles naturels}

1. Analyse des $F_{1}$ thélygènes à l'aide du croisement $\left(C R F_{2}\right)$ :

$\hat{o}$ issu d'une descendance $T_{f} \times q(A)$

Nous avons montré dans l'étude de la population de Nice (JuchaulT \& LEGRAND, $1981 \mathrm{~b}$ ) que la thélygénie $\mathrm{T}_{\mathrm{f}^{\prime}}$ (à femelles masculinisables) peut parfois offrir une transmission patrocline. Afin de quantifier ce phénomène, nous rappellerons ici les données précédentes en y adjoignant de nouveaux résultats. Toutes les données se rapportent à des descendances niçoises sauf celles relatées (tabl. 1) en (j) et (k), qui sont d'origine niortaise.

Lorsque, dans une filiation, un mâle a transmis son caractère thélygène à ses filles, ces dernières, en étant croisées soit avec un frère reconnu comme non thélygène, soit avec un mâle amphogène, peuvent donner naissance à des mâles thélygènes. De telles descendances ont été comptées, dans le cadre de la transmission patrocline de la thélygénie, comme des $F_{1}$ puisqu'une transmission matrocline a relayé l'hérédité patrocline.

L'équation d'un croisement aboutissant à une descendance thélygène est :

$$
\text { ô } \mathrm{ZZ} \times \text { néo- } q \mathrm{ZZ}_{\mathrm{f}^{\prime}} \rightarrow \text { néo- } q \text { \& } \mathrm{ZZ}_{\mathrm{f}^{\prime}}+\text { quelques } \hat{\text { ô }} \text { ô } \mathrm{ZZ}_{\left(\mathrm{f}^{\prime} \text { on } 0\right)}
$$

Le taux de néo- $q$ obtenu pour $\mathrm{N}$ descendants $=$ (nombre de $q$ \% $\mathrm{N}$ ) $\times 100\left(1^{\prime}\right)$.

Le croisement entre un mâle thélygène et une femelle amphogène $\left(\mathrm{CRF}_{2}\right)$ peut être représenté par l'équation :

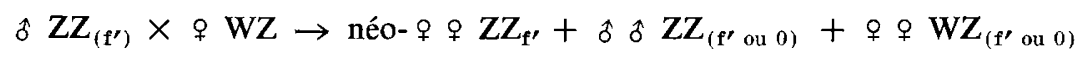

L'égalité ainsi prévue entre individus $\mathrm{ZZ}$ et $\mathrm{WZ}$ pour $\mathrm{N}$ descendants permet de calculer le taux moyen de néo-femelles:

$$
2 \text { (nombre de } q \text { - } \mathrm{N} / 2 \text { ) } / \mathrm{N} \times 100
$$

Le taux initial de néo-femelles répond en (a), (b), (f), (g), (h), (i) et (j) à la formule (1'). Celui des descendances (c), (d), (e) [qui sont issus du CRF $\mathrm{F}_{2}$ (b) $8 \hat{\delta} \quad 77$ 웅 par croisements des mâles avec leurs sœurs], $\left(\mathrm{k}_{1}\right)$ et $\left(\mathrm{k}_{2}\right)$ [qui sont issues du $\mathrm{CRF}_{2}$ (j) $10 \hat{o} 133$ o $1 \hat{o} \mathrm{og}$, par croisement des mâles avec des femelles amphogènes] ainsi que les taux de néo-femelles de tous les $\mathrm{CRF}_{2}$ répondent à la formule (2'). Il est à remarquer que lorsque ce taux répond à la formule $\left(2^{\prime}\right)$ et est inférieur à 50 , la descendance n'est thélygène que grâce à la présence de 50 p. 100 de femelles génétiques WZ.

Les résultats sont résumés dans le tableau 1. 


\section{TABLeaU 1}

Transmission de la thélygénie par les mâles naturels.

Etude des croisements $\left(C R F_{2}\right)$ entre les mâles d'une descendance thélygène et des femlles amphogènes.

Transmission of thelygeny by the males of natural populations.

Study of crosses $\left(C R F_{2}\right)$ between the males of a thelygenic progeny and amphogenic females.

\begin{tabular}{|c|c|c|c|c|}
\hline $\begin{array}{c}\text { Sex-ratio }(\hat{\delta} / q) \\
\text { initiale }\left(F_{1}\right)\end{array}$ & $\begin{array}{l}\text { Taux de } \\
\text { néo- } q \text { \& } \\
\text { en } F_{1}\end{array}$ & $\begin{array}{c}\text { Nature } \\
\text { des } \mathrm{CRF}_{2}\end{array}$ & $\begin{array}{c}\text { Sex-ratio } \\
\text { des } \mathrm{CRF}_{2} \mathrm{~T}\end{array}$ & $\begin{array}{c}\text { Taux } \\
\text { de néo- } q \text { ? } \\
\text { dans } \\
\text { ies } \mathrm{CRF}_{2} \mathrm{~T} \\
\end{array}$ \\
\hline (a) $8 / 248$ & 96,8 & $2 \mathrm{~T}$ & $\begin{array}{c}125 / 302 \\
0 / 84\end{array}$ & $\begin{array}{l}41,4 \\
100\end{array}$ \\
\hline (b) $1 / 40$ & 97,5 & $1 \mathrm{~T}$ & $\begin{array}{c}4 / 131-8 / 77 \\
0 / 218 \\
\end{array}$ & $\begin{array}{c}77-83 \\
100 \\
\end{array}$ \\
\hline (c) $2 / 212 \ldots \ldots \ldots \ldots \ldots$ & 99 & $2 \mathrm{~A}$ & 一 & 一 \\
\hline (d) $4 / 229$ & 98,3 & $2 \mathrm{~T} / 2 \mathrm{~A}$ & $\begin{array}{c}10 / 211-6 / 49 \\
2 / 67-1 / 72\end{array}$ & $\begin{array}{l}90,9-78,1 \\
94,2-97,2\end{array}$ \\
\hline (e) $26 / 207 \ldots \ldots \ldots \ldots \ldots$ & 88,8 & $1 \mathrm{~T} / 12 \mathrm{~A}$ & $26 / 50$ & 31,5 \\
\hline (f) $4 / 95$ & 95,9 & $1 \mathrm{~T} / 1 \mathrm{~A}$ & $26 / 110-18 / 83$ & $65,1-64,3$ \\
\hline (g) $3 / 11$ & 78,5 & $1 \mathrm{~A}$ & 一 & - \\
\hline (h) $3 / 64$ & 95,5 & $1 \mathrm{~T}$ & 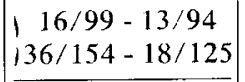 & $\begin{array}{l}72,1-75,7 \\
62,1-74,8 \\
\end{array}$ \\
\hline (i) $9 / 106$ & 92,5 & $1 \mathrm{~T} / 2 \mathrm{~A}$ & $4 / 72$ & 89,4 \\
\hline (j) $34 / 106$ & 75,7 & $4 \mathrm{~T}$ & $\begin{array}{c}11 / 41 \\
20 / 99 \\
15 / 64 \\
10 / 133+1 \delta_{\text {og }} \\
\end{array}$ & $\begin{array}{l}57,7 \\
66,3 \\
62 \\
84,7\end{array}$ \\
\hline$\left(\mathrm{k}_{1}\right) 46 / 104+2$ of $\ldots$ & 36,8 & $4 \mathrm{~A} / 7$ stériles & - & 一 \\
\hline$\left(\mathrm{k}_{2}\right) 46 / 368+1 \delta \mathrm{og}$ & 77,3 & $\begin{array}{c}3 \mathrm{~T} / 4 \mathrm{~A} \\
+9 \text { stériles }\end{array}$ & $\begin{array}{c}17 / 291-12 / 110 \\
107 / 211-57 / 80 \\
40 / 76\end{array}$ & $\begin{array}{c}88,9-80,3 \\
32,7-16,7 \\
31 \\
\end{array}$ \\
\hline
\end{tabular}

T : Descendance thélygène.

Thelygenic progeny.

A : Descendance amphogène.

Amphogenic progeny.

Les sex-ratio disposées sur la même ligne, ou reliées par une accolade, correspondent aux croisements d'un même mâle avec 2 à 4 femelles.

The sex ratios given on the same line, or linked by a bracket, correspond to the crossing of one male with 2 to 4 females. 
2. Analyse des descendants d'un mâle thélygène

a) Mâles fils

Des mâles obtenus dans certaines des descendances $T_{f^{\prime}}$ précédentes $\left(\mathrm{CRF}_{2}\right)$ c'est-à-dire des fils de mâles pouvant être qualifiés de thélygènes, ont été, à leur tour, croisés avec des femelles (A) pour voir s'ils ont hérité du caractère de leur père. Les données obtenues et les taux de néo-femelles calculés avec la formule ( $\left.2^{\prime}\right)$ sont résumés dans le tableau 2.

\section{TABLEAU 2}

Transmission de la thélygénie par les fils de ồ thélygènes naturels.

Transmission of thelygeny by the sons of thelygenic males of natural populations.

\begin{tabular}{|c|c|c|c|c|}
\hline $\begin{array}{l}\text { Sex-ratio d'origine } \\
\left(\mathrm{CRF}_{2}\right)\end{array}$ & $\begin{array}{c}\text { Taux } \\
\text { des néo- } 9 \text { o } \\
\text { des } \mathrm{CRF}_{2}\end{array}$ & $\begin{array}{c}\text { Nature } \\
\text { des } \mathrm{CRF}_{3}\end{array}$ & $\begin{array}{c}\text { Sex-ratio } \\
\text { des } \mathrm{CRF}_{3} \mathrm{~T}\end{array}$ & $\begin{array}{c}\text { Taux } \\
\text { des néo- } \hat{\delta} \\
\text { des } \mathrm{CRF}_{3}\end{array}$ \\
\hline (b) $8 / 77$ & 81,1 & $3 \mathbf{A}$ & - & - \\
\hline (j) $15 / 64 \ldots \ldots \ldots$ & 62 & $1 \mathrm{~T} / 5 \mathrm{~A}$ & $36 / 57$ & 22,5 \\
\hline (j) $10 / 133+1 \delta \delta_{o g}$ & 84,7 & $4 \mathrm{~T} / 4 \mathrm{~A}$ & $\begin{array}{r}90 / 136 \\
48 / 70 \\
52 / 108 \\
*\left\{\begin{array}{l}47 / 113 \\
48 / 92 \\
44 / 91\end{array}\right.\end{array}$ & $\begin{array}{l}20,3 \\
18,6 \\
35 \\
41,2 \\
31,4 \\
34,8\end{array}$ \\
\hline$\left(\mathrm{k}_{2}\right) \quad 17 / 291 \quad \ldots \ldots$ & 88,9 & $4 \mathrm{~T} / 5 \mathrm{~A}$ & $\begin{array}{l}61 / 89 \\
37 / 60 \\
94 / 133 \\
21 / 38\end{array}$ & $\begin{array}{l}18,6 \\
23,7 \\
17,2 \\
28,8\end{array}$ \\
\hline
\end{tabular}

Même légende que dans le tableau 1.

Symbols as in table 1.

$\mathrm{CRF}_{\mathrm{a}}$ : Croisement d'un $\hat{s}$ thélygène avec une $o$ amphogène.

Cross between a thelygenic male and an amphogenic female.

$\mathrm{CRF}_{3}$ : Croisement d'un fils de mâle thélygène avec une femelle amphogène.

Cross between $a$ son of $a$ thelygenic male and an amphogenic female.

* Ces trois descendances ont été obtenues par croisement d'un $\hat{o}$ og avec 3 femelles.

These three progenies arose from crossing an og male with 3 females.

b) Mâles petits-fils

A partir de la descendance 37 \& 60 \& (en italique dans le tableau 2), 14 mâles ont été croisés chacun avec 2 femelles (A). Tous ces croisements ont donné lieu à de l'amphogénie (en tout : 1035 ô 1058 ㅇ). 
c) Cas des femelles filles

a) A partir du CRF. 8 o 77 \& (tabl. 1 b) qui a montré le caractère thélygène du mâle issu de la $F_{1}: 1$ o 40 \&, 3 descendances thélygènes $\left(\begin{array}{lllll}2 & \delta & 212 & \wp & \text { - }\end{array}\right.$

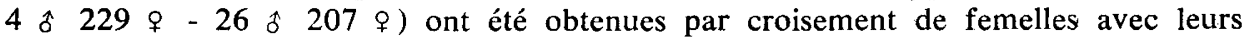
frères. Les mêmes mâles frères, croisés avec des femelles (A), n'ayant pas transmis la thélygénie (cf. tabl. 2), le caractère thélygène grand-paternel a été hérité et transmis par les femelles.

B) A partir des 3 descendances thélygènes précitées, ont été effectués, d'une part, les croisements des mâles avec des femelles (A) relatés dans le tableau 1 en (c) (d) (e), d'autre part, des croisements entre ces mêmes mâles et leurs sœurs.

$\beta_{1}$ - Les deux mâles issus de la descendance (c) comportant $2 \hat{\delta} 212$ q (qui n'ont pas transmis la thélygénie) croisés chacun avec une de leurs sœurs, ont offert des descendances thélygènes $\left(\begin{array}{lllll}52 & q & -55 & \hat{\sigma} & 100\end{array}\right)$. Le caractère thélygène grandpaternel a donc également été hérité et transmis par les femelles.

$\beta_{2}$ - A partir de la descendance (d) comprenant 4 o 229 \%, nous avons vu que deux de ces mâles ont transmis la thélygénie, mais que les deux autres ne l'ont pas transmise. 3 des croisements effectués entre ces mâles et leurs sœurs ont été thélygènes : avec les 2 mâles thélygènes : 11 \& 53 et 60 ; avec le mâle non thélygène : $6 \hat{o} 80 \%$; le $4^{\mathrm{e}}$ croisement (effectué avec un mâle non thélygène) a été amphogène : $124 \hat{o} 111$ ㅇ.

$\beta_{3}$ - Partant de la descendance (e) comportant 26 \& $207 \%$, nous avons vu que sur 13 mâles croisés avec des femelles (A), 1 seul a transmis la thélygénie. Or 11 croisements entre frères et sœurs effectués avec les mâles non thélygènes ont donné : 8 descendances thélygènes (en tout : 44 \& 560 \&), 2 arrhénogènes, dont une presque pure (67 $\hat{\delta} \quad 34 \&-177 \hat{\delta} 1 \%$ ), et 1 allélogène (Al) avec augmentation du taux des mâles au cours des portées successives ( 3 portées en 1 an) : 56 ô 84 \&, 51 \&ै 28 , 87 ô $9 \%$. Un dernier croisement effectué avec le mâle ayant transmis la thélygénie, a donné (en un an) une descendance allélogène : $14 \delta$, puis $27 \hat{\delta} 32$ \%

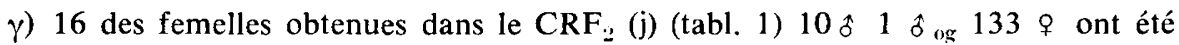
croisées par 2 avec un mâle (A).

Les descendances obtenues sont hétérogènes : 6 sont amphogènes, 2 arrhénogènes, les 8 autres thélygènes. Les 2 descendances $\operatorname{Ar}_{\mathrm{f}}$ sont hétérogènes $\left(\chi^{2}=5,56\right.$ pour 1 d.l.); il en est de même des 8 descendances $T_{f},\left(\chi^{2}=132\right.$ pour 7 d.1.). Les paires de descendances obtenues avec un même mâle réalisent toutes les combinaisons (A - Ar ; A - $\mathrm{T}_{\mathrm{f}^{\prime}} ; \mathrm{A}-\mathrm{A} ; \mathrm{T}_{\mathrm{f}^{\prime}}-\mathrm{T}_{\mathrm{f}^{\prime}} ; \mathrm{T}_{\mathrm{f}^{\prime}}-\mathrm{Ar}$ ) (à l'exception de Ar - Ar, qui serait sans doute possible avec un nombre plus important de descendances).

- Les 2 descendances $\operatorname{Ar}_{\mathrm{f}}$ offrent une allélogénie remarquable, à savoir la disparition progressive, puis totale, des néo-femelles. Elle est particulièrement prononcée chez l'une d'elles :

La $1^{\text {re }}$ année, la génitrice a donné 3 portées : 124 \&े 24 \& 92 ô 10 120 o 6 o et la seconde année (toujours sans être refécondée) : $101 \delta$.

L'autre descendance $\operatorname{Ar}_{\mathrm{f}}$ a donné : 127 \&े 31 \& puis 41 ô 3 \& (en 1 an).

- Il n'en est pas de même à l'intérieur d'une même descendance thélygène : les différentes portées constituent un ensemble homogène, exemples : 
- $1^{\text {re }}$ femelle (3 portées)

28 \& 75 ㅇ -33 \& 61 ㅇ -26 के 73 ㅇ $\left(\chi^{2}=2,18\right.$ pour 2 d.1.)

- $2^{\text {e }}$ femelle (également 3 portées)

7 oิ $106 q-24$ o 1 of og $137 q-15$ of $125 \%\left(\chi^{2}=5,13\right.$ pour 2 d.1.)

- $3^{\mathrm{e}}$ femelle

* la première année : 32 ô 52 \& - 39 \& 54 q

* la deuxième année : 31 \& 36 \& $\left(\chi^{2}=1,02\right.$ pour 2 d.l.)

Cette homogénéité montre que le taux des néo-mâles ne varie pas au cours des portées successives composant ces descendances thélygènes, même d'une année à l'autre.

Il est à remarquer que 6 descendances (une amphogène et 5 thélygènes) ont comporté des $\hat{\delta}$ og :

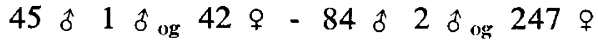

$$
\begin{aligned}
& 18 \text { oै } 1 \text { के } \mathrm{og} 80 \text { 우 }-46 \text { ô } 2 \text { के } \mathrm{og} 104 \text { 우 } \\
& 46 \delta 1 \delta \text { og } 368 \text { \& }-61 \delta 2 \delta \mathrm{og} 150 \text { ㅇ }
\end{aligned}
$$

Les 3 autres descendances thélygènes sont dépourvues de $\hat{\delta}$ og : 13 ô $199 \%$ 102 of 142 ㅇ -87 수 209 우.

\section{B. Transmission de la thélygénie $T_{f}$ par des néo-mâles expérimentaux}

A partir de la descendance thélygène niçoise comportant 2 ô 206 \&, 3 néomâles ont été obtenus par implantation de glande androgène chez de jeunes femelles et ont été croisés chacun avec 2 femelles (A).

Un seul néo-mâle a été fécond et a donné 2 descendances thélygènes : $6 \hat{o}$ 162 우 et 18 ㅇ.

C. Transmission de l'arrhénogénie $A r_{f}$ par des néo-mâles expérimentaux

a) Partant de la descendance niortaise arrhénogène imparfaite (Av 45) : $87 \hat{\delta}$ 60 ㅇ, 6 néo-mâles ont été obtenus expérimentalement. Croisés chacun avec 1 ou 2 femelles (A), ils ont donné les descendances suivantes :

- 77 \& 163 \%

-78 \& 117 웅 66126 ㅇ

-51 \& 72 ㅇ

- 45 \&े 75 ㅇ -147 ô 211 우

$-151 \%-59$ \& 86 우

-18

Les 7 descendances offrant une thélygénie imparfaite constituent un ensemble homogène $\left(\chi^{2}=7,4\right.$ pour 6 d.1.) (en tout : 523 of 850 \%).

b) Partant d'une descendance niortaise comportant 30 ô 18 \%, 6 néo-mâles expérimentaux ont été croisés chacun avec une femelle (A). 5 des descendances constituent un ensemble homogène ne différant pas significativement de l'amphogénie 
$\left(\chi^{2}\right.$ versus la sex-ratio $1 / 1=3,54$ pour 1 d.l.) (79 of $83 \& \quad-99$ o 117 o

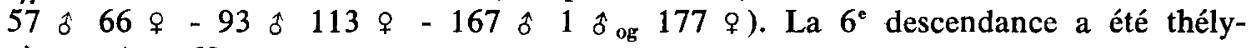
gène : 4 ô 62 \%.

D. Etude de la filiation matrocline de la thélygénie $T_{f^{\prime}}$

La filiation résumée dans le tableau 3 a été étudiée à titre de comparaison avec les résultats de la transmission patrocline de la thélygénie.

\section{TABleau 3}

Filiation matrocline de la thélygénie $T_{f}$.

Matroclinic transmission of $T_{f}$ thelygeny.

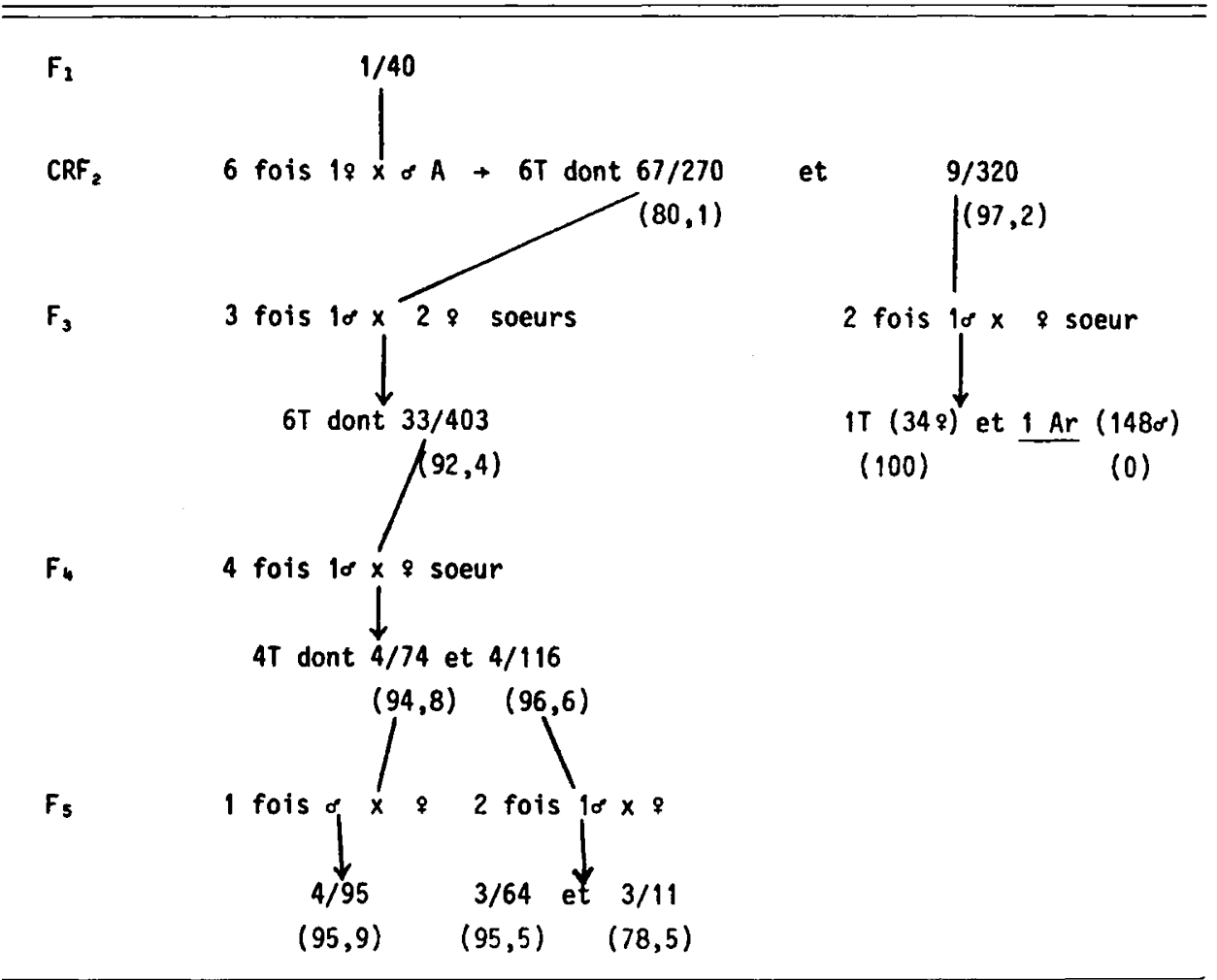

Les nombres entre parenthèses correspondent aux taux de néo-femelles calculés selon la formulation $1^{\prime}$ (voir texte).

Numbers between brackets give the proportions of neo-females, calculated according to formulation $I^{\prime}$ (see text). 


\section{E. Données concernant la relation entre la bactérie $F$ et le facteur $f$}

1. Apparition d'une descendance Ar dans la descendance d'une femelle amphogène infestée expérimentalement par $F$

Après implantation chez une femelle (A) - fécondée par un mâle (A) - de tissus prélevés chez une femelle $T_{F}$, la descendance a été thélygène $(2 \hat{o}, 23 q)$, conformément aux résultats décrits précédemment (LeGRAND \& Juchault, 1970). L'analyse des filiations ultérieures des 14 femelles filles est relatée dans le tableau 4.

\section{TABleaU 4}

Etude de la descendance d'une femelle amphogène infestée expérimentalement par la bactérie $F$ et croisée avec un mâle amphogène.

Study of the progeny of an amphogenic female experimentally infected with bacterium $F$ and crossed with an amphogenic male.

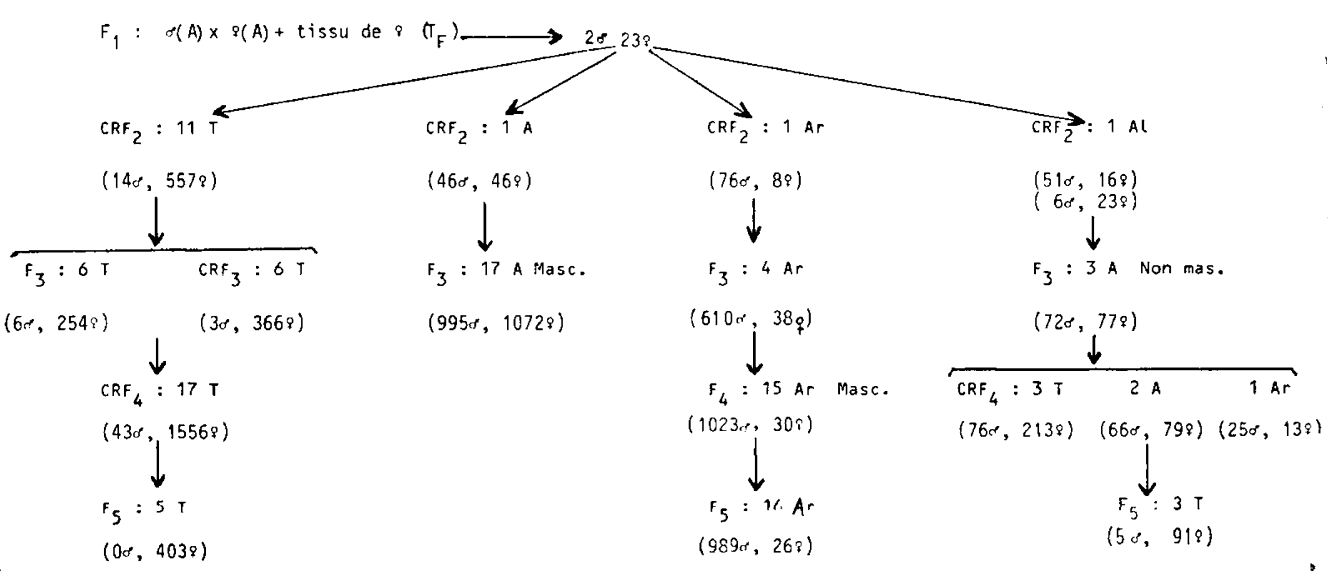

$\mathrm{T}$

A

Descendance thélygène.

Thelygenic progeny.

: Descendance amphogène. Amphogenic progeny.

$\mathrm{Ar}$

: Descendance arrhénogène.

Arrhenogenic progeny.

$\mathrm{Al} \quad$ : Descendance allélogène.

Allelogenic progeny.

$\mathrm{CRF}_{2}, \mathrm{CRF}_{3}, \mathrm{CRF}_{4}$ : Croisements entre un $\hat{o} \mathrm{~A}$ et une $q$ issue de la génération précédente.

Crosses between an $\boldsymbol{A}$ male and a female from the preceding generation.

$F_{3}, F_{4}, F_{5} \quad:$ Croisements entre frères et sœurs nés de la génération précédente. Crosses between brothers and sisters born in the preceding generation.

Masc.

: o masculinisable. Masculinisable female.

Non masc.

: ㅇ réfractaire à la masculinisation. Non-masculinisable female. 
2. Données résultant de l'étude d'une nouvelle population d'Armadillidium vulgare : celle d'Argenton-sur-Creuse (Indre)

Cette population a été étudiée à partir d'une récolte de 139 mâles, 337 femelles, 13 intersexués effectuée par G. MarTiN. Les descendances de 52 femelles fécondées dans la nature se sont ainsi réparties : 23 ont été du type $\mathrm{Ar}_{\mathrm{f}}, 26$ du type $\mathrm{T}, 2$ autres du type $\mathrm{Al}$, à femelles masculinisables; une seule descendance peut être qualifiée de pseudoamphogène ( 73 mâles, 61 femelles, 5 intersexués) dont les femelles sont masculinisables; elle a conné en $F_{2 .}: 2$ descendances $\mathrm{T}, 7 \mathrm{Ar}$ et $2 \mathrm{Al}$, ce qui confirme le caractère pseudoamphogène de la génération précédente. Sur 12 descendances $F_{1}$ $T$ testées, 3 appartiennent au type $T_{F}$ d'après la nature des intersexués et/ou l'état réfractaire des femelles à la masculinisation; les 9 autres recèlent le facteur $\mathrm{f}^{\prime}$ car les femelles sont masculinisables.

Dans la descendance d'une femelle $T$ ayant donné 38 os, 155 o et 9 intersexués, dont 2 (iM = mâles stériles à glandes androgènes hypertrophiées et gonopodes réduits) sont caractéristiques de la lignée $T_{F}$ (LegRAND \& JUChaulT, 1969 a), 8 des femelles filles se sont montrées réfractaires à la masculinisation, tandis qu’une autre a été masculinisée.

\section{Discussion}

\section{A. Mode de transmission des facteurs féminisants $f-f^{\prime}$}

- La transmission matrocline de la thélygénie à femelles masculinisables $\left(T_{f^{\prime}}\right)$ est bien établie, avec de rares exceptions dues à l'apparition d'une arrhénogénie, ainsi que le montre la filiation étudiée au § D (tabl. 3). Un exemple analogue a été donné dans une étude précédente (Juchaul T \& LEgRand, 1976).

Le taux des néo-femelles est très important : les données concernant cette filiation étudiée pendant 5 générations montrent que le taux est compris entre 78 et 100 p. 100 et le plus souvent supérieur à 90 p. 100 .

- Les résultats exposés au $\S$ A.1 dans le tableau 1 confirment, en les amplifiant, les données précédentes (Juchault et al., 1980) montrant que des mâles nés dans une $F_{1}$ thélygène possèdent et transmettent le facteur féminisant $\mathrm{f}^{\prime}$; ils échappent phénotypiquement à son influence, peut-être en raison de leur génotype. Ainsi, sur 44 mâles issus de descendances $T_{f^{\prime}}$, testés par croisement avec une femelle (A), 16 (soit environ 1/3) peuvent être qualifiés de thélygènes.

- Cette transmission patrocline ne s'arrête pas là : les croisements relatés en A.2.a et dans le tableau 2 montrent que certains fils d'un père thélygène peuvent également recevoir et transmettre le facteur féminisant lors de leur croisement avec une femelle (A). C'est ce qui a été observé pour 9 des 26 mâles testés, soit également environ $1 / 3$ d'entre eux.

- Par contre, aucun des 14 petits-fils issu d'un aïeul et d'un père tous deux thélygènes, testés en A.2, n'a transmis la thélygénie.

- Comme le montrent les descendances étudiées en A.2.c, les mâles thélygènes 
issus d'une $F_{1} T_{f^{\prime}}$, transmettent le facteur féminisant à leurs filles. Celles-ci confor-

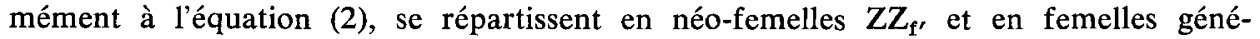
tiques WZ. Les néo-femelles $Z_{\mathrm{f}^{\prime}}$ ne doivent leur phénotype sexuel qu'à cette transmission, rendue évidente par les calculs précédents (montrant un excédent de femelles par rapport au nombre $\mathrm{N} / 2$ prévu par l'équation). Malheureusement, faute de gènes liés au sexe, les femelles génétiques, WZ, ne peuvent être distinguées des néo-femelles. La question posée est la suivante : peut-on estimer que les femelles WZ héritent et transmettent le facteur féminisant?

Les résultats consignés en A.2.c permettent de quantifier ce type de transmission matrocline du facteur $\mathrm{f}^{\prime}$ relayant l'hérédité patrocline.

Il est possible de distinguer, dans ces résultats, 2 types de croisements :

- L'ensemble $(\alpha)+(\beta)$ correspond à des croisements internes à la population de Nice puisque les $F_{1} T_{f^{\prime}}$ sont originaires de cette population et qu'il en est de même de la souche amphogène.

- L'ensemble $(\gamma)$ correspond à des croisements entre individus des populations niortaise (AV 45) et niçoise (souche amphogène).

\section{Ensemble $\alpha+\beta$}

Pour 18 croisements n'offrant aucun apport de génotype extérieur à la population niçoise, on compte 17 descendances où la femelle a transmis des facteurs féminisants hérités soit de son père (en $\alpha$ ), soit de son grand-père (en $\beta$ ). C'est dans ce dernier cas que se situent, à côté de descendances $\mathrm{T}$, des descendances $\mathrm{Ar}$ et $\mathrm{Al}$ qui marquent un affaiblissement du taux de transmission de ces facteurs. Les descendances Ar et $\mathrm{Al}$ ne peuvent provenir que du croisement : $\hat{o} \mathbf{Z Z} \times$ néo- $q \mathrm{ZZ}$. Les descendances $\mathbf{T}$ correspondent au croisement d'un $\hat{o} \mathbf{Z Z}$ avec, soit une néo- $q \mathbf{Z Z}_{f^{\prime}}$, soit une femelle $\mathrm{WZ}_{\mathrm{f}^{\prime}}$. Dans l'ignorance de la nature de la femelle, on ne peut calculer le taux exact de néo-femelles mais il est possible d'en connaître les limites, en considérant successivement les 2 hypothèses : la femelle sœur est $\mathrm{WZ}$ ou elle est $\mathrm{ZZ}_{\mathrm{f}}$.

Les calculs (non relatés ici) montrent que la quasi totalité des petites filles ont fortement transmis les facteurs féminisants. Ceci tranche nettement avec l'absence de transmission par les petits-fils.

Si la femelle est WZ et n'a pas hérité du facteur féminisant, son croisement avec un mâle ZZ doit aboutir à de l'amphogénie. L'unique descendance amphogène (en $\beta_{2}$ ) est probablement imputable à une telle femelle.

\section{Ensemble $\gamma$}

Les 16 descendances obtenues $(6 \mathrm{~A}, 2 \mathrm{Ar}, 8 \mathrm{~T})$ dérivent de femelles nées dans le $\mathrm{CRF}_{2}$ comportant $10 \hat{o} 1 \hat{o}$ og 133 o et répondant à l'équation (2).

Il est donc possible d'escompter que les 16 génitrices se répartissent en WZ et en néo-femelles $\mathrm{ZZ}_{\mathrm{f}^{\prime}}$. Il est à remarquer que la réalisation de la plupart des combinaisons en matière de sex-ratio dans les 2 descendances d'un même mâle (A) avec 2 femelles hybrides (A - Ar ; A - $\left.T_{f^{\prime}}-A-A ; T_{f^{\prime}}-T_{f^{\prime}} ; T_{f^{\prime}}-A r\right)$ est imputable à une hétérogénéité des femelles. 
Dans la descendance à l'origine des croisements, sur $N=144$ individus, le nombre moyen de femelles $\mathrm{WZ}$ est $\mathrm{N} / 2=72$; celui des néo-femelles $Z_{\mathrm{f}^{\prime}}$, est donc : $133-72=61$. Ainsi, sur 16 femelles employées, on pouvait escompter 8 à 9 femelles génétiques et 7 à 8 néo-femelles $\mathrm{ZZ}_{\mathrm{f}}$. Si l'on considère que les 6 descendances amphogènes sont issues des femelles WZ, les 2 descendances $\mathrm{Ar}$ et les 8 descendances $T$, de néo-femelles $Z Z$, les résultats ne diffèrent pas significativement de cette prévision $\left(\chi^{2}=1,78-\right.$ d.1. $\left.=1\right)$.

Une série de croisements effectuée à partir d'une des descendances amphogènes (98 o 110 \&) semble confirmer la nature WZ de la génitrice de cette descendance. En effet 35 femelles ont donné, en étant croisées avec des mâles frères, de l'amphogénie. Ce maintien de l'amphogénie serait conforme à des croisements : ô $\mathbf{Z Z} \times q \mathrm{WZ}$. Cependant, une de ces descendances a été thélygène (17 $\hat{\delta} \quad 52 \%)$, ce qui indiquerait que certaines femelles $\mathrm{WZ}$ héritent du facteur féminisant.

Il apparaît cependant que certaines femelles WZ - semble-t-il plus fréquemment les hybrides Niort-Nice - n'héritent pas et/ou ne transmettent pas le facteur $\mathrm{f}^{\prime}$. Le mécanisme de ce phénomène est inconnu.

\section{Descendance d'un ồ}

Un cas particulier est offert par la descendance du $\hat{o}$ og apparu (tabl. 1) (j). Il a donné, en étant croisé avec 3 femelles $(\mathrm{A})$, des descendances thélygènes homogènes n'offrant aucun $\hat{o}_{\mathrm{og}}$ (en tout $139 \hat{o}^{2} 296 \%$ ). S'il s'agit d'un $\hat{o}_{\mathrm{og}} \mathbf{Z Z}_{(\mathrm{f}) \mathrm{m}}$ croisé avec des femelles WZ, la descendance comporte 36 p. 100 de néo-femelles. Le facteur $\mathrm{m}$, considéré comme masculinisant, n'aurait donc pas été transmis. Une autre façon d'interpréter le résultat est de considérer le $\hat{\sigma}_{\text {og }}$ comme un néo-mâle $W Z_{m}$. Dans ce cas, son croisement avec les femelles WZ aurait dû donner $1 \hat{o} / 3 \%$; il y aurait donc environ 30 femelles génétiques transformées en néo-mâles ( 8 p. 100). Des $\hat{\delta}$ og exceptionnels sont également apparus en $\mathrm{CRF}_{3}$. Le seul dont la «descendance 》 ait été étudiée s'est révélé stérile (comme 7 mâles normaux de la même descendance). Quoi qu'il en soit, l'interprétation de ces résultats doit être différente de celle d'une étude précédente (Juchault \& Legrand, 1976 b), dans laquelle $m$ a pu êre rapporté à un gène capable d'inhiber l'action des déterminants femelles portés par le chromosome $\mathrm{W}$ chez une femelle génétique sur 2 (du fait que ce gène existe généralement à l'état hétérozygote dans une descendance $\mathrm{Ar}_{\mathrm{m}}$ ). Les $\hat{\delta}_{\mathrm{og}}$ exceptionnels pourraient être des «ratés» d'une féminisation des mâles par le facteur $f$, ce qui expliquerait qu'ils ne redonnent pas d'intersexués dans leur descendance.

\section{Transmission des facteurs féminisants par un néo-mâle expérimental}

- Le résultat - malheureusement unique - obtenu en B montre que l'inversion expérimentale $d u$ sexe d'une néo-femelle $T_{f^{\prime}}$ n'inhibe pas la transmission du facteur $f^{\prime}$.

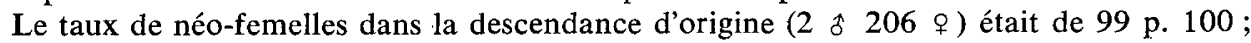
les taux observés dans les descendances du néo-mâle $(92,8$ et 100 p. 100) ne diffèrent pas significativement du taux d'origine.

- Les résultats exposés en C.a concernant la transmission du facteur f par les néo-mâles expérimentaux $\mathrm{Ar}_{\mathrm{f}}$ montrent tout d'abord que la constitution de ces néomâles est incompatible avec la formule $\mathrm{WZ}_{\mathrm{f}}$ car le croisement de tels individus avec une femelle $W Z$ de souche (A) :

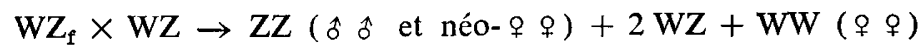


aurait conduit, en (a), dans l'ensemble constitué de descendances thélygènes imparfaites, à un taux de mâles inférieur à 25 p. 100, du fait de l'inversion sexuelle d'une partie d'entre eux sous l'action du facteur $f$. Le taux obtenu est très supérieur (38 p. 100). Ces croisements doivent donc répondre à l'équation :

$$
\mathrm{ZZ}_{\mathrm{f}} \times \mathrm{WZ} \rightarrow \mathrm{WZ}(\text { ㅇ } q)+\mathrm{ZZ}_{\mathrm{f}} \text { ( } \hat{\text { ô }} \hat{o} \text { et néo- } q \text { \%) }
$$

Le nombre de néo-femelles est approximativement de $850-1 / 2(523+850)$, et leur taux est de l'ordre de 23,8 p. 100. Il est inférieur à celui de la lignée d'origine (Av 45), où il était de 40,8 p. 100.

La thélygénie imparfaite correspond donc, en fait, à la transmission d'un facteur $\mathrm{f}$ caractéristique de l'arrhénogénie.

Il est cependant apparu 2 descendances $T_{f^{\prime}}$ pures $(151 \%-18 \%)$. Ainsi, de même qu'un néo-mâle $T_{f^{\prime}}$ peut transmettre le facteur $\mathrm{f}^{\prime}$ qui conditionne le phénotype sexuel de la néo-femelle dont il provient expérimentalement, un néo-mâle $\mathbf{A r}_{\mathrm{f}}$ expérimental transmet également le facteur féminisant $\mathrm{f}$. Ce résultat paraît trancher sur celui que l'on observe habituellement dans les croisements : $\hat{o} \operatorname{Ar}_{\mathfrak{r}} \times$ 을 (A), à savoir l'amphogénie de telles descendances qui semble impliquer une absence générale du facteur $\mathrm{f}$ chez un mâle $\mathrm{Ar}_{\mathrm{f}}$. La plupart des croisements C.b paraissent conformes à cette règle. Cependant, si l'on considère leur total, le $\chi^{2}$ versus la sex-ratio $1 / 1(3,54)$ est proche de la significativité et traduit le fait que, dans les 5 croisements, le nombre de mâles est toujours inférieur à celui des femelles. Ceci peut signifier qu'il existe des néo-femelles $\mathbf{Z Z}_{\mathrm{f}}$ (de l'ordre de 2,9 p. 100), c'est-à-dire que le néo-mâle expérimental a conservé et transmis le facteur $\mathrm{f}$ responsable du phénotype sexuel de la néo-femelle dont il provient.

\section{B. Relations entre les facteurs $f$ et $f^{\prime}$, nature de ces facteurs}

Si les termes extrêmes des descendances monogènes à femelles masculinisables : la thélygénie $\mathrm{T}_{\mathrm{f}^{\prime}}$ et l'arrhénogénie $\mathrm{Ar}_{\mathrm{f}}$, sont bien tranchés et ont été rapportés (JuchaulT et al., 1980) à l'action de 2 facteurs féminisants, l'un à transmission régulière, $\mathrm{f}^{\prime}$, inversant la quasi totalité des individus $\mathrm{ZZ}$ d'une descendance, en néo-femelles, l'autre, labile, $f$, dont la disparition permet la réalisation de nombreux mâles, la présente étude apporte des données suggérant un passage, semble-t-il dans les deux sens : de $f^{\prime}$ à $\mathrm{f}$ et $\operatorname{de} \mathbf{f}$ à $\mathrm{f}^{\prime}$.

\section{Possibilité d'un passage de f' à $f$}

- En prenant comme critère de ce passage l'affaiblissement du taux de néofemelles en dessous de 50 p. 100 du nombre d'individus $Z Z$ (ce qui, dans un croisement : $\hat{z} \mathrm{ZZ} \times$ néo- $q \mathrm{ZZ}$ correspondrait effectivement à de l'arrhénogénie), les résultats des croisements $A .1$ et $A .2$ en suggèrent de nombreux exemples. Un facteur de thélygénie, apporté par une néo-femelle à certains de ses fils, s'il est parfois transmis avec la même stabilité par ces derniers, est fréquemment atténué. Il a cependant été observé dans le tableau 1 en (a) que les descendances offertes par un même mâle thélygène avec 2 femelles (A) peuvent être, l'une thélygène pure (84 $\%)$, l'autre

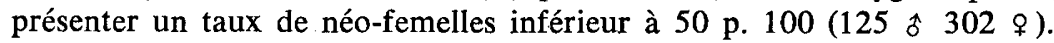

- Le phénomène est encore plus accentué dans la descendance des fils de mâle. thélygène : tous les taux de néo-femelles sont très inférieurs à 50 p. 100. 
La disparition des néo-femelles dans la descendance des petits-fils d'un mâle thélygène confirme qu'il s'agit bien, dans les générations précédentes, d'un affaiblissement progressif de la transmission des facteurs féminisants. Ceux-ci paraissent donc passer d'un type stable (f') a un type labile (f).

Le même phénomène s'observe dans la transmission matrocline relayant l'hérédité patrocline :

- Nous avons vu en A.2.c. $\beta 3$ l'apparition de 2 descendances $\operatorname{Ar}_{f}$ - dont une presque pure $\left(\begin{array}{llll}77 & \delta & 1 & \text { o }\end{array}\right)$ - et de 2 descendances $A l$ en $F_{4}$ de la $F_{1} T_{f^{\prime}}: 1$ o 40 o tandis que 8 autres $F_{4}$ sont $T_{f^{\prime}}$. Les 2 descendances $A l$ sont très significatives à l'égard d'un passage de la thélygénie à l'arrhénogénie : la première portée offre, dans les 2 cas, une thélygénie. Les portées suivantes sont arrhénogènes dans un cas, la $2^{\mathrm{e}}$ portée est pseudoamphogène dans l'autre cas (ces portées se succédant à quelques semaines d'intervalle).

- Il en est de même en A.2.c. $\gamma$ : partant de la descendance $\mathrm{Tf}_{\mathrm{f}^{\prime}}$ d'un seul mâle

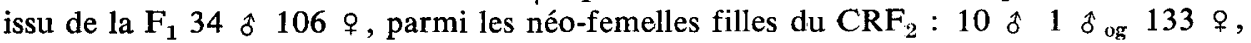
certaines ont donné de la thélygénie forte, tandis que 2 autres offraient - en étant croisées, comme leurs sœurs, avec un mâle (A) - de l'arrhénogénie forte.

\section{Possibilité d'un passage de $f$ à $f^{\prime}$}

Ce phénomène paraît s'être présenté dans la descendance de certains néo-mâles expérimentaux $\mathrm{Ar}_{\mathrm{f}}$ relatée en $\mathrm{C} . \mathrm{a}$, où sont apparues deux descendances $\mathrm{T}_{f^{\prime}}$ pures parmi les $\mathrm{Ar}_{\mathrm{f}}$. Ce fait est à rapprocher des résultats obtenus précédemment (JUCHAULT et al., 1980), dans une expérience de sélection, poursuivie pendant 6 générations, précisément à partir de la descendance Av 45, origine des néo-mâles expérimentaux utilisés ici. Cette sélection a abouti à séparer des lignées ${A r_{f}}_{f}$ et $T_{f^{\prime}}$, après passage par ćs $s$ descendances pseudoamphogènes.

Le même cas s'est reproduit en C.b, où, partant d'une descendance à la limite de la pseudoamphogénie (30 ô 18 ९ ), un des néo-mâles expérimentaux a donné une descendance $T_{f}$, tandis que ses frères ont offert de la pseudoamphogénie (avec probablement apparition de quelques néo-femelles $\mathrm{ZZ}_{\mathrm{f}}$ ). On doit s'interroger sur l'hétérogénéité, en $\mathrm{C} . \mathrm{a}$, de la descendance d'un même néo-mâle $\mathrm{Ar}_{\mathrm{f}}$ avec 2 femelles (A) : l'une, du type $\mathrm{T}_{\mathrm{f}^{\prime}}$ pur (151 $\left.q\right)$, l'autre offrant un nombre important de mâles (59 o 86 o ) et environ 18,6 p. 100 de néo-femelles, ce qui correspond à une descendance de type $\mathrm{Ar}_{\mathrm{f}}$. C'est un phénomène analogue à celui qui a été relaté dans le tableau 1 en (a), mais la descendance d'origine était thélygène.

La disjonction ainsi observée par deux fois dans la descendance d'un même mâle avec 2 femelles (A) peut signifier que $f$ et $\mathrm{f}^{\prime}$ sont seul et même facteur, dont l'expression est conditionnée par l'apport génétique des femelles (A). Cependant, une autre interprétation est possible : les 2 mâles en question sont des mosaïques germinales et les deux émissions de sperme dérivent de spermatogonies situées dans des zones différentes de la gonade.

\section{Nature des facteurs féminisants $f$ et $f^{\prime}$}

Le problème essentiel réside dans la question : $\mathrm{f}$ et $\mathrm{f}^{\prime}$ sont-ils des facteurs génétiques ou épigénétiques? L'ensemble des données précédentes permet-il de trancher la question : $f$ et $\mathrm{f}^{\prime}$ représentent-ils des polygènes sur lesquels peut agir la sélection 
pour contrôler les taux de femelles et de mâles dans une population, ou bien $f$ et $f^{\prime}$ sont-ils 2 états différents de la relation hôte-élément épigénétique?

a) Arguments en faveur de l'hypothèse : $f$ et $f$ 'sont des polygènes

- Les mâles naturels, dans un croisement avec une femelle (A), sont parfois capables de transmettre la thélygénie $T_{f}$, avec la même efficacité que les femelles. S'ils la transmettent souvent moins bien peut s'expliquer par le fait qu'ils représentent une sélection des génotypes les moins féminisants parmi la gamme des génotypes possibles.

- L'atténuation de la transmission des facteurs féminisants par les fils de mâles thélygènes, puis sa disparition chez les petits-fils peut s'expliquer par le renforcement progressif chez ces hybrides $\left(\hat{o} \mathbf{T}_{f^{\prime}} \times \subsetneq \mathrm{A}\right)$ du génotype caractéristique de la souche (A). Le génotype de cette souche peut être différent de celui des lignées thélygènes où la sélection a favorisé les gènes qui renforcent le facteur $\mathrm{f}^{\prime}$ responsable de l'inversion sexuelle des mâles.

On observe d'ailleurs également quelques indices d'une altération de la transmission du facteur $\mathrm{f}^{\prime}$ chez les femelles hybrides résultant du croisement : $\delta$ (A) $\times \& T_{f^{\prime}}$. Nous en avons noté une au $\S \mathrm{D}$ consistant en l'apparition d'une descendance $\mathbf{A r}_{\boldsymbol{f}}$ pure dans une filiation thélygène. Il apparaît également des descendances $\mathrm{Ar}_{\mathrm{f}}$ en lignée maternelle lors de l'introduction du génotype (A) dans le génotype $T_{f^{\prime}}$ (en A.2.c. $\gamma)$.

- Un néo-mâle expérimental $T_{f^{\prime}}$ (en fait : un seul exemple) transmet la thélygénie avec la même efficacité, dans le croisement avec une femelle (A), que s'il était resté femelle. En ce qui concerne les néo-mâles expérimentaux $\mathrm{Ar}_{\mathrm{f}^{\prime}}$, ils transmettent mieux les facteurs féminisants que ne le font les mâles naturels (qui, eux, ne transmettent aucun facteur f) et, semble-t-il, aussi bien qu'une femelle $\mathbf{A r}_{\mathrm{f}}$. Ceci peut s'expliquer par le fait qu'un néo-mâle expérimental conserve un génotype femelle, c'est-à-dire offrant une sélection des génotypes les plus féminisants parmi la gamme des génotypes possibles.

\section{b) Arguments en faveur de l'hypothèse : $f$ et $f$ 'sont épigénétiques}

En ce point de l'exposé des résultats, le meilleur argument en faveur de l'hypothèse que $\mathrm{f}$ est épigénétique reste le phénomène d'allélogénie, à savoir l'augmentation du taux des mâles au cours des portées successives d'une même femelle fécondée par un seul mâle.

Ce phénomène peut même être poussé à l'extrême, à savoir une $1^{\text {re }}$ portée entièrement thélygène, suvie d'une portée arrhénogène.

Dans d'autres cas - et parfois seulement la $2^{\mathrm{e}}$ année - la femelle ne donne naissance qu'à des mâles (cf. A.2.c. $\gamma$ ).

Une explication fondée sur une sélection gamétique au cours du vieillissement des spermatozoïdes stockés dans le réceptacle séminal de la femelle est improbable : en effet, une telle évolution de la sex-ratio des portées n'intervient pas chez une femelle $T_{f}$ (cf. A.2.c. $\gamma$ ).

Une autre explication serait possible : en présence de certains génotypes, l'âge de la mère exerce une influence non génétique sur les ovocytes, qui modifie la sensi- 
bilité de l'embryon aux gènes féminisants. Cependant, une même femelle peut être thélygène dans sa $1^{\text {re }}$ portée avant d'être, à quelques semaines d'intervalle, arrhénogène. L'exemple donné ici est loin d'être unique : Juchault et al. (1980) en ont donné de nombreux autres où l'on peut mettre en doute l'effet de l'âge de la femelle car il y a eu alternance de l'arrhénogénie et de la thélygénie, exemple :

83 ô $10 \%$ puis 18 ô 55 $q$ la $1^{\text {re }}$ année, 51 के $5 \%$ puis 20 ô la $2^{\mathrm{e}}$ année.

Dans la recherche d'une explication au phénomène de monogénie, avant de découvrir la bactérie F, nous avions (LEGRAND \& Juchault, 1969 b) invoqué les similitudes entre le mode de transmission des facteurs féminisants et les données concernant le virus $\sigma$, responsable de la sensibilité au $\mathrm{CO}^{2}$ chez la drosophile, données résumées dans la publication de L'Héritier (1962) et d'OHANESSIAN-Guillemain (1963). Malgré certaines divergences, la comparaison est toujours valable, en particulier, maintenant que sont connus les états $f$ et $f^{\prime}$ des néo-femelles masculinisables.

En ce qui concerne les convergences on peut citer :

- L'existence d'une labilité du facteur $\mathrm{f}$ chez les femelles arrhénogènes d'A. vulgare rappelle de façon frappante le cas des mouches femelles non stabilisées (où la transmission du virus à la descendance décroît avec l'âge), par opposition à ce qui se passe en général, chez les femelles thélygènes, où la transmission de $\mathrm{f}^{\prime}$ est régulière, ce qui rappelle le cas des mouches stabilisées.

- Le passage de l'état stabilisé à l'état non stabilisé s'observe accidentellement dans la transmission matrocline du virus $\sigma$.

Ceci peut rappeler, chez $A$. vulgare, le passage de la thélygénie à l'arrhénogénie

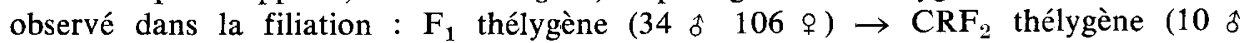
1 ô og 133 \&) $\rightarrow$ apparition de $\mathrm{CRF}_{3}$ arrhénogènes (la sex-ratio ne dépendant que de la femelle — dont la mère est la femelle amphogène —, et non du mâle $A$ ).

- De même, la possibilité du passage inverse, chez les mouches, de l'état non stabilisé à l'état néo-stabilisé, peut rappeler, chez $A$. vulgare, l'apparition de descendances thélygènes pures à partir d'un néo-mâle expérimental $\operatorname{Ar}_{\mathrm{f}}$. D'autres exemples de ce processus ont été donnés dans une publication précédente (Juchaulr et al., 1980).

- Le fait qu'un imago de mouche infesté soit sensible au $\mathrm{CO}^{2}$, ou non, dépend de son génotype. Un même mâle stablisé croisé avec 2 femelles peut offrir des descendances très différentes (si l'une offre le génotype re re). Ceci rappelle les descendances hétérogènes offertes par un même mâle d' $A$. vulgare croisé avec 2 femelles (A).

Des divergences apparaissent cependant, au vu des résultats de la présente étude :

- Si certains mâles ne transmettent pas le facteur $\mathrm{f}^{\prime}$ et d'autres le transmettent plus faiblement qu'une femelle, la transmission patrocline peut êre complète (cas des mâles ayant offert une descendance entièrement thélygène).

- Certains fils de mâles thélygènes transmettent - très faiblement d'ailleurs le facteur $\mathrm{f}^{\prime}$ (sous une forme comparable à $\mathrm{f}$ puisqu'elle conditionne l'apparition d'un taux de néo-femelles équivalent à une arrhénogénie). Cette transmission par les fils est totalement absente en ce qui concerne le virus $\sigma$.

Il n'existe pas d'équivalent, chez la drosophile, de la possibilité d'inverser une femelle en mâle, on ne peut donc pas comparer les résultats obtenus avec les néo-mâles expérimentaux d'Al. vulgare avec ceux qui concernent les mâles chez la drosophile. 
Ces divergences ne condamnent pas obligatoirement l'hypothèse que $f$ est un élément épigénétique et que $\mathrm{f}$ et $\mathrm{f}^{\prime}$ représentent deux états de la relation hôte-élément épigénétique, même si ce dernier n'est pas un virus mais - comme l'hypothèse l'a été proposée (Juchault et al., 1980) — résulte d'une implantation d'un plasmide de la bactérie $\mathbf{F}$ dans le génome de l'hôte.

\section{Données concernant la relation entre la bactérie $F$ et le facteur $f$}

\section{Apparition d'une descendance arrhénogène dans la descendance d'une femelle amphogène infestée par la bactérie $F$}

Parmi les 23 femelles obtenues dans la $F_{1}$ très thélygène issue d'une femelle génétique (WZ) (tabl. 4), doivent figurer environ une dizaine de néo-femelles $Z Z_{F}$, à côté de femelles génétiques ayant acquis - ou non - le facteur F. L'étude des générations ultérieures obtenues à partir de 14 des femelles de la $F_{1}$ nous renseigne sur leur constitution.

- Les croisements en retour $\left(\mathrm{CRF}_{2}\right)$ thélygènes obtenus par croisement de 11 femelles avec des mâles (A) sont évidemment issus d'individus - mâles ou femelles génétiques - infestés par la bactérie $F$, processus qui a perpétué la thélygénie au cours des générations ultérieures.

- La femelle $F_{1}$ non masculinisable à l'origine du $C R F_{2}$ allélogène a transmis le facteur $\mathbf{F}$ à un certain nombre de ses descendants. Compte tenu de la forte arrhénogénie de la première portée $\left(\begin{array}{lll}51 & \hat{o} & 16\end{array}\right)$, il est probable que cette génitrice était une néo-femelle $\mathrm{ZZ}_{\mathrm{F}}$. L'augmentation du taux de néo-femelles en $2^{\circ}$ portée résulte d'une progression de l'infestation de l'organisme - et en particulier des ovaires - par la bactérie. La transmission des bactéries s'est poursuivie en $F_{3}$ car, malgré l'amphogénie des 3 descendances obtenues, le fait que les femelles ne sont pas masculinisables montre qu'elles récèlent le facteur $F$. Le même phénomène s'est poursuivi dans le croisement en retour des femelles de la $F_{3}$ avec un mâle (A) $\left(C_{R} F_{4}\right)$ car, malgré l'amphogénie de l'un des $C_{R F}$, les $3 F_{5}$ qui en sont issues sont thélygènes.

- La femelle $F_{1}$ à l'origine du $\mathrm{CRF}_{2}$ amphogène devait être une femelle génétique exempte de bactéries, ainsi que le prouve le maintien de l'amphogénie dans les 17 descendances constituées de femelles masculinisables obtenues en $F_{3}$.

- La descendance la plus intéressante est le $\mathrm{CRF}_{2}$ arrhénogène. La génitrice ne peut être qu'une néo-femelle dont le croisement correspond à l'équation :

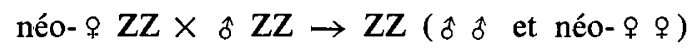

La forte arrhénogénie ainsi apparue s'est montrée transmissible, comme le prouvent les filiations ultérieures qui comportent 23 descendances ne comptant que des mâles, sur 43 croisements effectués, de la $F_{2}$ à la $F_{5}$.

Les résultats des tests physiologiques effectués sur 4 des femelles issues de la $F_{4}$, à savoir la réussite de la masculinisation, prouve que ces néo-femelles ne recèlent pas le facteur $\mathrm{F}$. Ces critères : néo-femelles masculinisables transmettant une arrhénogénie fréquemment totale sont caractéristiques de la présence du facteur $f$.

Une première hypothèse, étant donné le caractère unique de ce résultat, est 
que l'arrhénogénie découle d'une mutation apparue dans la souche amphogène, c'est-à-dire que $f$ est un gène. Cependant, en 15 générations, cette souche s'est toujours montrée parfaitement stable.

Une deuxième hypothèse — sans doute plus vraisemblable étant donné la remarque précédente - est que $\mathrm{f}$ a été introduit par l'implantation, dans la femelle (A), de tissus prélevés sur la femelle donneuse $T_{F}$. Quelle peut être, dans ce cas, la nature de ce facteur?

- Compte tenu des données apportées dans le présent travail, et notamment des convergences entre le mode de transmission de la monogénie et celui du virus $\sigma$, le facteur $\mathrm{f}$ pourrait être un virus. La bactérie $\mathrm{F}$ étant étroitement liée à la forme de thélygénie inductible par implantation et se traduisant par l'apparition de néofemelles non masculinisables, il faudrait admettre que, dans ce cas, le virus agit sur son superhôte, l'oniscoïde, et se propage en étant associé à la bactérie. Le facteur F ne serait donc pas la bactérie, mais l'association bactérie-virus. Il pourrait exister à l'état de provirus dans la bactérie ; activé, il entrerait en phase végétative et détruirait la bactérie lysogène $F$. Le fait que nous n'ayons jamais observé de particules virales dans les bactéries ou les ovocytes n'est pas une preuve suffisante, puisqu'on connaît des virus défectifs : les états $\varrho$ et ultra- $\varrho$ du virus $\sigma$. Sous sa forme de "virus génétique »- c'est-à-dire $\mathrm{f}$ - le virus serait devenu indépendant de la bactérie, donc directement associé aux cellules de l'oniscoïde. Sous cette forme, il serait incapable d'être propagé par inoculation. Comme les états $\varrho$ et ultra $\varrho$ du virus $\sigma$, il resterait cependant propagé héréditairement. Les femelles d'Armadillidium possédant f étant masculinisables, il faudrait admettre que, dans cet état, le virus n'aurait pas les mêmes propriétés : il continuerait à inhiber les déterminants sexuels mâles, responsables de la différenciation de la glande androgène, mais non plus le fonctionnement des systèmes de neurosécrétion contrôlant la croissance d'un implantat de cette glande et la libération de l'hormone androgène, d'où l'absence d'hypertrophie et le fonctionnement normal de cet implantat (et la possibilité de masculiniser la néo-femelle $\mathbf{Z Z}_{\mathrm{f}}$ ). On peut également penser que c'est la bactérie elle-même qui est responsable des effets sur un implantat, le virus n'agissant que sur le territoire androgène embryonnaire, en inhibant sa différenciation en glande.

- Une autre hypothèse - qui ne fait pas intervenir un virus susceptible de n'être jamais observé s'il est toujours défectif — est que f correspond à l'intégration d'un plasmide bactérien dans le génome de l'oniscoïde. Certes, l'existence d'une telle intégration dans une cellule d'eucaryote est un phénomène encore très peu connu. A notre connaissance, le seul exemple établi concerne le règne végétal, en l'occurrence le crown gall (revue in Gautheret, 1959). Néanmoins de tels plasmides ont été invoqués pour expliquer les phénomènes de stérilité mâle chez les végétaux (revue in Pearson, 1981).

Dans le cadre de l'hypothèse : f est un plasmide bactérien, la différence rappelée ci-dessus entre les propriétés de la bactérie sous sa forme végétative et celles du plasmide pourrait s'expliquer par le fait que ne s'intègre aux cellules de l'oniscoïde qu'un fragment de l'ADN bactérien.

\section{Données résultant de l'étude de la population d'Argenton-sur-Creuse}

L'étude des descendances des 52 femelles récoltées dans la nature permet d'affirmer le caractère monogène de toutes les femelles de cette population, ce qui 
rend très probable l'absence de femelles génétiques. S'il existait en effet des femelles WZ transmettant $F$, elles donneraient naissance à des femelles exemptes de facteurs épigénétiques - comme le sont les mâles issus de portées $T_{F}$ - ce qui aboutirait à une amphogénie vraie, transmissible. Un argument purement mathématique vient appuyer l'hypothèse d'une disparition des femelles génétiques. Ces dernières, lorsqu'elles sont croisées avec un mâle normal, donnent 50 p. 100 de femelles. Une néo-femelle $\mathrm{ZZ}_{\mathrm{F}}$ ou $\mathrm{ZZ}_{\mathbf{f}^{\prime}}$ en donne jusqu'à $100 \mathrm{p}$. 100 , ce qui avantage considérablement ce type de détermination du sexe, du moins si les facteurs $F$ et $f^{\prime}$ sont suffisamment stables - ce qui est le cas, d'après l'étude de très nombreuses filiations des femelles thélygènes.

La population dArgenton-sur-Creuse, qui semble offrir une prépondérance de $\mathrm{f}^{\prime}$ sur $F$, apparaît comme intermédiaire entre les populations poitevines (Niort), où $F$ prédomine largement sur $\mathrm{f}^{\prime}$, et celles de Moulis et de localités espagnoles, où $\mathrm{F}$ est absent et où ne subsistent que les lignées $\mathrm{Ar}_{\mathrm{f}}$ et $\mathrm{T}_{\mathrm{f}^{\prime}}$ (Juchault et al., $1980 \mathrm{a}$, Juchault \& Legrand, 1981 a et b).

Le résultat susceptible de concerner une transformation de $F$ en $f$ est l'apparition d'une femelle masculinisable dans la descendance d'une néo-femelle $T_{F}$ (non masculinisable).

Si la mère était - comme probable - une néo-femelle $\mathrm{ZZ}_{\mathrm{F}}$, l'ovocyte à l'origine de la néo-femelle masculinisable a dû offrir une transformation de $F$ en $f$ (la descendance ne peut être étudiée chez une femelle masculinisée à l'état pubère).

\section{Conclusion générale}

Si les données complémentaires apportées par cette étude n'apportent pas une solution définitive au problème du mécanisme de la monogénie chez les Oniscoïdes, du moins fournissent-elles des éléments de réponse.

Les facteurs féminisants $\mathrm{f}$ et $\mathrm{f}^{\prime}$, respectivement responsables de l'arrhénogénie $\mathrm{Ar}_{\mathrm{f}}$ et de la thélygénie $T_{f^{\prime}}$ à néo-femelles masculinisables (par opposition à la thélygénie $T_{F}$ accompagnant la présence d'une bactérie, qui rend les néo-femelles non masculinisables) offrent - ainsi que nous l'avions déjà signalé - des modalités de transmission rappelant celles du virus $\sigma$. Le facteur $f^{\prime}$ peut être comparé à l'état stabilisé, le facteur $\mathbf{f}$ à l'état non stabilisé du virus. Le passage de $\mathrm{T}_{f^{\prime}}$ à $\mathrm{Ar}_{\mathrm{f}}$, comme dans le cas du virus $\sigma$, peut dépendre du génotype de l'hôte. La sélection naturelle pourrait donc, en agissant sur ce génotype, contrôler le rapport des sexes dans une population d'Armadillidium vulgare, en assurant une prédominance des femelles, mais en maintenant un taux suffisant de mâles. Les données génétiques concernant le mode de transmission des facteurs $f$ et $f^{\prime}$ sont cependant insuffisantes pour trancher la question : s'agit-il uniquement de polygènes ou réellement de facteurs épigénétiques dont l'effet est contrôlé par le génome?

Un résultat encore unique concernant l'apparition d'une descendance arrhénogène $A r_{f}$ chez une femelle amphogène implantée de tissus de néo-femelle $T_{F}$ suggère l'apport, chez la receveuse, d'un élément issu de la bactérie $F$. Cet élément peut être soit un virus défectif associé à la bactérie (dans ce cas le facteur $F$ responsable de la thélygénie $T_{F}$, serait l'ensemble bactérie + virus), soit un plasmide bactérien qui ne 
représenterait qu'un fragment du chromosome bactérien. Ce fragment d'ADN conserverait la propriété essentielle d'inhiber la différenciation de la glande androgène chez les mâles génétiques infestés.

L'étude d'une nouvelle population d'A. vulgare, celle d'Argenton-sur-Creuse, apporte une donnée complémentaire, concernant une relation possible entre la bactérie $F$ - ou un virus - et le facteur f.

L'absence d'infestation des ovocytes par le plasmide bactérien — ou le virus dans les ovocytes peut rendre compte de la disparition des femelles, au profit d'un taux croissant de mâles, dans les portées successives d'une néo-femelle $\mathrm{Ar}_{\mathrm{f}}$ fécondée par un seul mâle, c'est-à-dire fournir une explication à l'allélogénie.

L'hypothèse selon laquelle $f$ et $\mathrm{f}^{\prime}$ sont des facteurs épigénétiques représentant 2 états de la relation hôte-élément épigénétique, reçoit un appui indirect venant de l'étude de la sex-ratio dans les descendances issues de 17 populations d'Armadillidium vulgare.

Dans les populations - comme celle de Niort - où les femelles génétiques WZ semblent disparues (et avec elles l'amphogénie), populations où prédomine une thélygénie due à l'infestation de l'organisme par la bactérie $F$, les mâles fonctionnels proviennent presque exclusivement des lignées $\mathrm{Ar}_{\mathrm{f}}$. Ces dernières étant caractérisées par une raréfaction progressive des néo-femelles arrhénogènes, la survie de la population dépend d'un mécanisme assurant le renouvellement de ces dernières. Une transformation $\mathrm{F} \rightarrow \mathrm{f}$ assurerait donc le maintien d'un certain taux de mâles. Dans d'autres populations, où la bactérie a totalement disparu (exemple : Moulis) sa disparition serait évidemment suicidaire pour l'espèce (réduite à des mâles) si ne subsistait pas un mécanisme générateur de femelles, qui pourrait être un plasmide bactérien (ou un virus génétique) $\mathrm{f}^{\prime}$, ce facteur étant susceptible de se transformer en une forme labile, f, génératrice de mâles.

Or il existe un parallèle saisissant, en matière de composition des descendances, y compris quant aux types d'intersexués, entre les populations comportant les unes, essentiellement des descendances $T_{F}$ et $A r_{f}$ (exemple Niort), d'autres, des descendances $T_{F}, T_{f^{\prime}}$ et $A_{f}$ (Celles-sur-Belle, Argenton-sur-Creuse), d'autres enfin, uniquement $T_{f^{\prime}}$ et $\operatorname{Ar}_{\mathrm{f}}$ (Moulis). Il est ainsi difficile de croire au hasard ayant établi, selon la région, des mécanismes de détermination du sexe totalement indépendants les uns des autres, à savoir : soit un mécanisme mixte associant la bactérie productrice de femelles et un polygène $f$ fournissant les mâles, soit la bactérie et des polygènes fournissant mâles et femelles, pour finir par les seuls mécanismes génétiques lorsque la bactérie a disparu.

On peut se demander comment serait né, seulement chez quelques espèces d'Oniscoïdes et même uniquement dans certaines populations d'une espèce comme $A$. vulgare, un système purement génétique si complexe - et si rare dans l'échelle animale - en l'absence d'un événement fortuit initial : l'infestation par une bactérie ayant probablement entraîné par sélection la disparition des femelles génétiques (du fait que ces dernières ne donnent que 50 p. 100 de femelles, tandis qu'une néo-femelle $T_{F}$ en fournit, en moyenne, plus de 90 p. 100).

Certes, les Crustacés Isopodes, et en particulier les Oniscoïdes, offrent une grande variabilité de déterminisme homo-hétérogamétique du sexe, ainsi qu'il a été rappelé dans l'introduction de cette étude. On connaît également des cas d'inversion du sexe, 
contrôlés génétiquement, qui pourraient expliquer un passage de l'hétérogamétie femelle à l'hétérogamétie mâle tel qu'il se présente chez Porcellio dilatatus (Legrand et al., 1980 et 1974 b). De telles inversions du sexe sont également fréquentes chez Idotea balthica (LEGRAND-HAMELIN \& LEGRAND, 1982 a et b) mais, paradoxalement, s'il existe une inversion des mâles en néo-femelles, c'est l'inversion du sexe femelle qui semble la plus fréquente, principalement chez la sous-espèce $I$. $b$. tricuspidata. La sex-ratio de la population n'en est d'ailleurs pas modifiée car, ainsi que l'ont montré mathématiquement EsHel \& FELdMANN (1982) les néo-mâles WZ, croisés avec leurs sœurs, donnent, en $F_{2}$ une prépondérance de femelles, notamment du fait de l'existence des femelles WW. S'il existe donc une possibilité d'établissement de polygènes contrôlant le sexe, cela ne veut pas dire qu'ils agissent toujours seuls en l'absence de facteurs épigénétiques : l'intervention de facteurs épigénétiques, a pu développer, par sélection, le contrôle génétique de leurs effets sur une base prééxistante.

Le fait que dans certaines régions (Nice, beaucoup de populations espagnoles) s'observe un mécanisme de détermination du sexe fondé à la fois sur la monogénie à femelles masculinisables et sur l'homo-hétérogamétie, pour reposer enfin exclusivement sur ce déterminisme ancestral (population espagnole de Valence, dont les populations d'Afrique du Nord : Tunis, Laghouat sont très proches), permet de reconstituer l'évolution du déterminisme du sexe chez $A$. vulgare telle que nous l'avons retracée dans une précédente publication (JuchaulT \& LEGRAND, 1981 b). Il semble qu'à l'heure actuelle la bactérie soit en régression, peut-être en fonction des conditions de l'environnement, notamment l'influence de l'homme. Dans le cadre de l'hypothèse précédente, elle laisserait cependant derrière elle son plasmide, ou son virus génétique, perpétué dans la lignée $T_{f^{\prime}}$ qui assure à la fois la production de femelles et le renouvellement des femelles productrices de mâles. On peut se demander si la persistance de la lignée amphogène n'est qu'un vestige temporaire d'un état ancestral en voie de régression, ou bien l'indice d'un retour à cet état ancestral. Son maintien dépendra du taux de production des descendances thélygènes et arrhénogènes.

Reçu le 17 janvier 1983.

Accepté le 20 septembre 1983.

\section{Références bibliographiques}

ANDERS F., 1957. Über die Geschlechtsbeeinflüssende Wirkung von Farballelen bei Gammarus pulex ssp subterraneus (Schneider). Z. Indukt. Abstamm. Vererbungsl., 88, 291-332.

Bulnheim H.P., 1965. Untersuchungen über Intersexualität bei Gammarus duebeni (Crustacea Amphipoda). Helgol. Wiss. Meeresunters., 12, 349-394.

Bulnheim H.P., 1971. Entwicklung, Ubertragung und Parasit - Wirtbeziehungen von Thelohania hereditaria sp. n. (Protozoa, microsporidia). Z. Parasitenkd., 35, 241-262.

DE LATTIN G., 1949. Ein Farbgen als relativer Geschlechtsrealisator bei Porcellio scaber (Isopoda). Naturwissenschaften, 36, 89-90.

DE LATTIN G., 1951. Über die Bestimmung und Vererbung des Geschlechts einiger Oniscoideen (Crust., Isop.). I. - Untersuchungen über die Geschlechtsbeeininflussende Wirkung von Farbfaktoren bei Porcellio und Tracheoniscus. Z. Vererblehre, 84, 1-37. 
DE Lattin G., 1952. Über die Bestimmung und Vererbung des Geschlechts einiger Oniscoideen (Crust. Isop.). II. - Zur Vererbung der Monogenie von Cylisticus convexus (Deg). Z. Indukt. Abstamm - Vererbungsl., 84, 536-567.

Eshel I., Feldmann W., 1982. On evolutionary genetic stability of the sex-ratio. Theor. Pop. Biol., 21, 430-439.

Gautheret R.J., 1959. La culture des tissus végétaux. Techniques et réalisations. Masson, Paris, 863 p.

Ginsburger-Vogel Th., 1973. Détermination génétique du sexe, monogénie et intersexualité chez Orchestia gammarella Pallas (Crustacé Amphipode Talitridae). I. - Phénomènes de monogénie dans la population de Penzé. Arch. Zool. Exp. Gén., 114, 397-438.

Ginsburger-Vogel Th., 1974. Détermination du sexe, monogénie et intersexualité chez Orchestia gammarella Pallas (Crustacé Amphipode Talitridae). II. - Etude des relations entre la monogénie et l'intersexualité. Influence de la température. Arch. Zool. Exp. Gén., 115, 93-127.

Ginsburger-Vogel Th., Carre-Lecuyer M.C., Fried-Montaufier H.C., 1980. Transmission expérimentale de la thélygénie liée à l'intersexualité chez Orchestia gammarellus (Pallas); analyse des génotypes sexuels dans la descendance des femelles normales transformées en femelles thélygènes. Arch. Zool. Exp. Gén., 121, 261-270.

Juchault P., Legrand J.J., 1964. Démonstration de l'homogamétie femelle par croisement de deux femelles génétiques chez les Oniscoïdes Porcellio dilatatus et Helleria brevicornis. C.R. Acad. Sci. Fr., 258, 2685-2686.

Juchault P., Legrand J.J., 1968. Rôle des hormones sexuelles, des neurohormones et d'un facteur épigénétique dans la physiologie sexuelle d'individus intersexués d'Armadillidium vulgare Latr. (Isopode Oniscoïde). C.R. Acad. Sci. Fr., 267, 2014-2016.

JuChault P., Legrand J.J., 1970. Intersexualité et monogénie chez les Crustacés isopodes terrestres : induction de la thélygénie chez Armadillidium vulgare; facteurs contrôlant le pseudo-hermaphrodisme masculin externe chez Porcellio dilatatus. Ann. Endocrinol., Paris, 31, 525-530.

Juchault P., Legrand J.J., 1972. Croisements de néo-mâles expérimentaux chez Armadillidium vulgare Latr. (Crustacé Isopode Oniscoïde). Mise en évidence d'une hétérogamétie femelle. C.R. Acad. Sci. Fr., 274, 1387-1389.

Juchault P., Legrand J.J., 1976 a. Modification de la sex-ratio dans les croisements entre différentes populations du Crustacé Armadillidium vulgare Latr. Notion de déterminisme polygénique et épigénétique du sexe. Arch. Zool. Exp. Gén., 197, 81-94.

Juchault P., Legrand J.J., 1976 b. Etude génétique de l'intersexualité des mâles à ouvertures génitales femelles chez l'Oniscoïde Armadillidium vulgare Latr. : interprétation et modalités de la transmission héréditaire. C.R. Soc. Biol., 170, 429-433.

Juchault P., Legrand J.J., 1978. Etude du fonctionnement de la glande androgène dans le cas d'implantations croisées entre deux espèces de Crustacés isopodes terrestres, Porcellio dilatatus Brandt et Armadillidium vulgare Latreille : notion de spécificité de l'hormone androgène et des neurohormones impliquées dans le contrôle de la fonction androgène. Gen. Comp. Endocrinol., 36, 175-186.

Juchault P., Legrand J.J., 1979. Analyse génétique et physiologique de la détermination du sexe dans une population du Crustacé Isopode Oniscoïde Armadillidium nasatum Budde-Lund. Arch. Zool. Exp. Gén., 120, 25-43.

Juchault P., Legrand J.J., 1981 a. Contribution à l'étude qualitative et quantitative des facteurs contrôlant le sexe dans les populations du Crustacé Isopode terrestre Armadillidium vulgare Latreille. II. - Populations hébergeant le facteur féminisant F (Bactéroïde intracytoplasmique). Arch. Zool. Exp. Gén., 122, 65-74.

Juchault P., Legrand J.J., 1981 b. Contribution à l'étude qualitative et quantitative des facteurs contrôlant le sexe dans les populations du Crustacé Isopode terrestre Armadillidium vulgare Latreille. III. - Populations n'hébergeant pas le facteur féminisant F (Bactéroïde intracytoplasmique). Arch. Zool. Exp. Gén., 122, 117-131.

Juchault P., Legrand J.J., MocQuard J.P., 1980 a. Contribution à l'étude qualitative et quantitative des facteurs contrôlant le sexe dans les populations du Crustacé Isopode 
terrestre Armadillidium vulgare Latreille. I. - La population de Niort (Deux-Sèvres). Arch. Zool. Exp. Gén., 121, 3-27.

Juchault P., Maissiat J., Legrand J.J., 1978. Caractérisation chimique d'une substance ayant les effets biologiques de l'hormone androgène chez le Crustacé Isopode terrestre Armadillidium vulgare Latreille. C.R. Acad. Sci. Fr., 286, 73-76.

Juchault P., Martin G., Legrand J.J., 1980 b. Induction par la température d'une physiologie mâle chez les néo-femelles et les intersexués du Crustacé Oniscoïde Armadillidium vulgare Latr., hébergeant un bactéroïde à action féminisante. Int. J. Invertebr. Reprod., 2, 223-235.

KatakuRa Y., 1967. Hormonal control of sex differentiation in the terrestrial Isopod, Armadillidium vulgare. Gunma Symp. Endocrinol., 4, 49-64.

Legrand J.J., Juchault P., 1969 a. Le déterminisme de l'intersexualité chez les Crustacés Isopodes terrestres : corrélation entre intersexualité et monogénie. C.R. Acad. Sci. Fr., 268, 1647-1649.

Legrand J.J., Juchault P., 1969 b. Le déterminisme de la monogénie chez les Oniscoïdes. C.R. Acad. Sc. Fr., 268, 1774-1777.

Legrand J.J., Juchault P., 1970. Modification expérimentale de la proportion des sexes chez les Crustacés Isopodes terrestres : induction de la thélygénie chez Armadillidium vulgare Latr. C.R. Acad. Sci. Fr., 270, 706-708.

Legrand J.J., Juchault P., 1974. Contribution à l'étude de la génétique du sexe chez les Oniscoïdes. Analyse des croisements entre deux sous-espèces de Porcellio dilatatus Brandt, l'une à hétérogamétie mâle, l'autre à hétérogamétie femelle. Arch. Zool. Exp. Gén., 115, 441-488.

Legrand J.J., Juchault P., Mocquard J.P., 1974 a. Analyse préliminaire du mécanisme de l'intersexualité féminisante chez le Crustacé Armadillidium vulgare Latr. (Isopode Oniscoïde). C.R. Acad. Sci. Fr., 278, 2979-2982.

Legrand J.J., Juchault P., Artault J.C., Mocquard J.P., Picaud J.L., 1974. Le statut systématique de la «forme» petiti Vandel de Porcellio dilatatus Brandt, récoltée à l'île Saint-Honorat (Alpes-Maritimes). Critères morphologiques, génétiques et physiologiques. Bull. Soc. Zool. Fr., 99, 461-471.

Legrand J.J., Juchault P., Mocquard J.P., Martin G., 1980. Polymorphisme d'origine géographique portant sur la "valence» des chromosomes sexuels et phénomènes de monogénie résultant du croisement de différentes populations de Porcellio dilatatus Brandt (Crustacé Isopode Terrestre). Reprod. Nutr. Dév., 20, 23-59.

Legrand-Hamelin E., Legrand J.J., 1982 a. Déterminisme génétique de l'inversion du sexe femelle accompagnant le croisement de deux sous-espèces d'ldotea balthica Pallas. I. - Résultats concernant les phénotypes albafusca, bilineata et uniformis. Reprod. Nutr. Dév., 22, 753-766.

Legrand-Hamelin E., Legrand J.J., 1982 b. Déterminisme génétique de l'inversion du sexe femelle accompagnant le croisement de deux sous-espèces d'Idotea balthica Pallas. II. - Résultats concernant le phénotype bilineata-lineata et son association avec le phénotype alba-fusca. Reprod. Nutr. Dév., 22, 889-904.

Legrand-Hamelin E., 1977. Obtention de néo-mâles fonctionnels et démonstration expérimentale de l'hétérogamétie femelle chez Idotea balthica (Crustacé Isopode). C.R. Soc. Biol., 171, 176-180.

L'Heritier Ph., 1962. Les relations du virus héréditaire de la Drosophile avec son hôte. Ann. Inst. Pasteur, 102, 511-526.

LUEKEN W., 1966. Autosomale Weibchendeterminierende Realisatoren bei Armadillidium nasatum (Isopoda terrestria). Z. Vererbungsl., 97, 352-355.

Martin G., 1981. Contribution à l'étude cytologique et fonctionnelle des systèmes de neurosécrétion des Crustacés Isopodes. Thèse Doctorat d'Etat, Université de Poitiers, $\mathrm{n}^{\circ} 331$.

Martin G., Juchault P., Legrand J.J., 1973. Mise en évidence d'un micro-organisme intra- 
cytoplasmique symbiote de l'Oniscoïde Armadillidium vulgare Latr. dont la présence accompagne l'intersexualité ou la féminisation totale des mâles génétiques de la lignée thélygène. C.R. Acad. Sci. Fr., 276, 2313-2316.

Mittal O.P., Pahwa S., 1980. Cytogenetical studies on two terrestrial isopods (Crustacea), Philoscia lodnensis Ramakrishna and Porcellio rathkei Brandt. Cytobios, 29, 17-24.

Mittal O.P., Pahwa S., 1981. Germ cell chromosomes in two species of terrestrial isopods from Indian. Experientia, 37, 343-344.

NiIYAma H., 1950. The X-Y mechanism of the sex chromosome in the male of Anisogammarus anadalei. Annot. Zool. Jap., 23, 58-62.

NiIYAma H., 1956. Cytological demonstration of an XO mechanisms in males of Tecticeps japonicus, an Isopod Crustacea. Cytologia, 21, 38-43.

Ohanessian-Guillemain A., 1963. Etude de facteurs génétiques contrôlant les relations du virus $\sigma$ et de la drosophile son hôte. Ann. Génét., 5, 1-64.

Pearson O.H., 1981. Nature and mechanisms of cytoplasmic male sterility in plants : a review. Hortscience, 16, 482-487.

Staiger H., Boceuet C., 1954. Cytological demonstration of female heterogamety in Isopods. Experientia, 10, 64-66.

StAiger H., BocQuet C., 1956. Les chromosomes de la super espèce Jaera marina F. et de quelques Janiridae (Isopodes Aselottes). Bull. Biol. Fr. Belg., 90, 1-32.

Tinturier-Hamelin E., 1963. Polychromatisme et détermination génétique du sexe chez l'espèce polytypique Idotea balthica (Pallas) (Isopode Valvifère). Cah. Biol. Mar., 4, 473-591.

VANDEL A., 1938. Recherches sur la sexualité des Isopodes. III. - Le déterminisme du sexe et de la monogénie chez Trichoniscus (spiloniscus) provisorius Racovitza. Bull. Biol. Fr. Belg., 72, 147-186.

VANDEL A., 1941. Recherches sur la génétique et la sexualité des Isopodes terrestres. VI. - Les phénomènes de monogénie chez les Oniscoïdes. Bull. Biol. Fr. Belg., 75, 316-363.

Vitaglian-Tadini G., 1963. La variabilità del rapporto sessi in Asellus aquaticus e la sua determinazione oligogenica. Atti Accad. Naz. Lincei, Cl. Sci. Fis., Mat. Nat., Rend.. 34, 573-582. 